\title{
Multilevel Mixed Effects Analysis of Individual and Community Factors Associated With Unmet Need for Contraception Among Married Women in Four East African Countries
}

\author{
Allen Kabagenyi ( $\sim$ allenka79@yahoo.com ) \\ Makerere University https://orcid.org/0000-0002-2185-7535

\section{Ronald Wasswa} \\ Makerere University School of Statistics and Planning \\ Nsobya Henry \\ Makerere University \\ Ariho Paulino \\ Makerere University \\ Julius Sseninde \\ Makerere University \\ Jean Christophe Rusatira \\ Johns Hopkins University Bloomberg School of Public Health
}

Research article

Keywords: Unmet need, Community, Burundi, Rwanda, Tanzania, Uganda, East Africa, Multilevel

Posted Date: May 6th, 2021

DOl: https://doi.org/10.21203/rs.3.rs-470884/v1

License: (c) (i) This work is licensed under a Creative Commons Attribution 4.0 International License.

Read Full License 
Multilevel mixed effects analysis of individual and community factors associated with unmet need for contraception among married women in four East African countries

Allen Kabagenyi ${ }^{1 *}$ Ronald Wasswa $^{2}$ Nsobya Henry ${ }^{1}$ Ariho Paulino ${ }^{1}$ Julius Sseninde $^{1}$ Jean Christophe Rusatira ${ }^{3}$

\section{Author addresses}

${ }^{1}$ Department of Population Studies, School of Statistics \& Planning, College of Business and Management Sciences, Makerere University, P.O. Box 7062, Kampala-Uganda

${ }^{2}$ Department of Statistical Methods and Actuarial Science, School of Statistics \& Planning, College of Business and Management Sciences, Makerere University, P.O. Box 7062, Kampala-Uganda.

${ }^{3}$ Bill \& Melinda Gates Institute for Population and Reproductive Health, Department of Population, Family and Reproductive Health, Johns Hopkins Bloomberg School of Public Health, Johns Hopkins University.

*Corresponding Author: allenka79@yahoo.com

\section{Author email addresses}

AK: allenka79@yahoo.com

RW: rwasswa93@yahoo.com

NH: lhenuga@yahoo.com

AP: arihopaulino@yahoo.com

JS: juliusprh@gmail.com

JCR: jrusati1@jhu.edu 


\section{Abstract}

Background: Although use of contraceptives is an expression of a woman's reproductive control, unmet need for contraception remains high and a public concern among married women in East Africa. Limited literature has explored the associated factors in the region. This study examined the individual and community level factors associated with unmet need for contraception among married women in Burundi, Rwanda, Tanzania and Uganda.

Methods: The study utilized data from the four most recent demographic and health surveys on the following selected samples of women in Burundi (8767), Rwanda (6472), Tanzania (7417) and Uganda (10288). Analyses were conducted using multilevel mixed effect logistic regressions with random community and country level effects.

Results: Findings showed that: 20\%, 22\%, 28\% and 33\% of the married women in Rwanda Tanzania, Uganda and Burundi respectively had unmet need for contraception. Young married women, low education level, low wealth quintile, higher number of living children, couples that are not staying together, husband's desire for more children, history of child death, women who are not working, no access to family planning messages, long distances to health facilities, and husbands as decision-makers on women's health care were associated with high level of unmet need for contraception. Also, low community wealth, low community use of modern contraceptives, higher community age at marriage, higher community mean number of living children and lower community age at sexual debut were found to be significantly associated with high risk of unmet need for contraception in at least one of the countries.

Conclusions: The findings suggest the need to design programs and policies that ensure awareness and access to modern contraceptive services among all disadvantaged communities and unique groups like couples who are not staying together through increased outreaches and increased mass media campaigns. In addition, concerted efforts aimed at raising the educational levels of people to bring about change in social and cultural norms that influence the husbands desire for higher number of children are much needed. Deliberate efforts of empowering women through education, job creation, and reproductive health decisions will significantly reduce the levels of unmet need for contraception in East Africa.

Keywords: Unmet need, Community, Burundi, Rwanda, Tanzania, Uganda, East Africa, Multilevel 


\section{Background}

Unmet need for family planning is defined as a proportion of married women who are neither pregnant nor postpartum amenorrheic and want to space their next birth at least for 2 years or prefer to stop childbearing but are not using contraceptives[1]; or women who are currently pregnant/postpartum amenorrheic but their current pregnancy/last birth was unwanted or mistimed [1]. In 2019, an estimated 190 million women wished to avoid pregnancies but were not using any contraceptive method globally [2]. This has become a major challenge especially in developing countries [3-5].

In sub-Saharan African countries, the overall modern contraceptive prevalence is lowest among currently married women than non-married women [5]. Studies have also showed a big difference between total wanted fertility and the actual fertility rate; for example, in Uganda and Tanzania, the total fertility rate of 4.3 and 4.5 was lower than the actual fertility rate of 5.4 and 5.2 respectively which implied that women still have unplanned pregnancies $[7,8]$.

The high unmet need for contraception among such married women is partly related to health risks, community influence, cultural beliefs and norms [8] and inability to access family planning services [9]. This has led to severe consequences including unplanned pregnancies [10] and high population growth rates especially in sub-Saharan region [3].

Different studies on unmet need have been done in several developing countries like: Ghana [11], Ethiopia [12], Nigeria [13], Cameroon [14], Burundi [15], Kenya [16] and Uganda [17]. However, few studies exploring both individual and community factors associated with unmet need for contraception among East African countries where the uptake of modern contraceptives is very low have been done. This study sought to add on the literature of unmet need for contraception among married women in Burundi, Rwanda, Tanzania and Uganda. Kenya was not considered in this study since according to its most recent demographic and health survey, more than half of its married women (58\%) were using contraceptives and its unmet need for contraception was at $18 \%$ [18]. This unmet need for contraception is low compared to that of its neighbors. Further, according to the Family Planning 2020 (FP2020) initiative, that evaluates the progress in family planning indicators among the least developed countries, of all the East African countries in the initiative, Kenya has had the most progress both in terms of the increase in uptake of modern contraceptives and demand satisfied thereby surpassing the set expectations [9].

Specifically, we set out to i) identify and examine the common individual and community level factors associated with unmet need for contraceptives among married women in the four East African countries and ii) assess the country variations in the factors that associated with unmet 
need for contraception. This was intended to inform regional and individual country strategies that can be implemented to reduce the level of unmet need for contraception among married women.

\section{Methods}

\section{Data source}

We used data from most recent demographic and health surveys (DHS) from Burundi, Rwanda, Tanzania and Uganda (2016-2017 Burundi DHS, 2014-2015 Rwanda DHS, 2015-2016 Tanzania DHS and 2016 Uganda DHS) in order to examine the individual and community level factors associated with unmet need contraception among sexually active fecund married women. The married women samples were based on nationally representative samples of 17,269; 13,497; 13,266 and 18,506 women aged 15-49 years of age for Burundi, Rwanda, Tanzania and Uganda respectively. The approval to download and use of these data sets was obtained from the Measure DHS website www.measuredhs.com upon request.

In the four countries, the DHS employed a two stage stratified sample design. The first stage comprised of a selection of enumeration areas (EAs) obtained from a list of clusters based on the most recent census in each country as the sampling frame. The second stage involved a systematic sampling of households within each cluster from which all women of child bearing age (15-49 years), who were either permanent residents of the households or visitors who slept in the households the night before the survey were eligible to be interviewed $[6,7,18,19]$. We excluded women who were never married, divorced, separated and widowed or infecund.

In this study, infecund women were defined as those women who were not pregnant or postpartum amenorrheic, and were either in marriage for 5 or more years, had no children in the past 5 years, and had never used contraception; responded "Can't get pregnant" regarding the desire for future children; said "menopausal/hysterectomy" as a reason for not using contraception; responded to time since last period as $\geq 6$ month, and not postpartum amenorrheic; responded to time since last period as "menopausal/hysterectomy" or "never menstruated", or "last period was before last birth", and last birth was over 5 years ago [1]. Such women were taken to have no need for family planning [1] and thus the reason for their exclusion. The figure below shows a final weighted sample size for each country that was used in the study. 


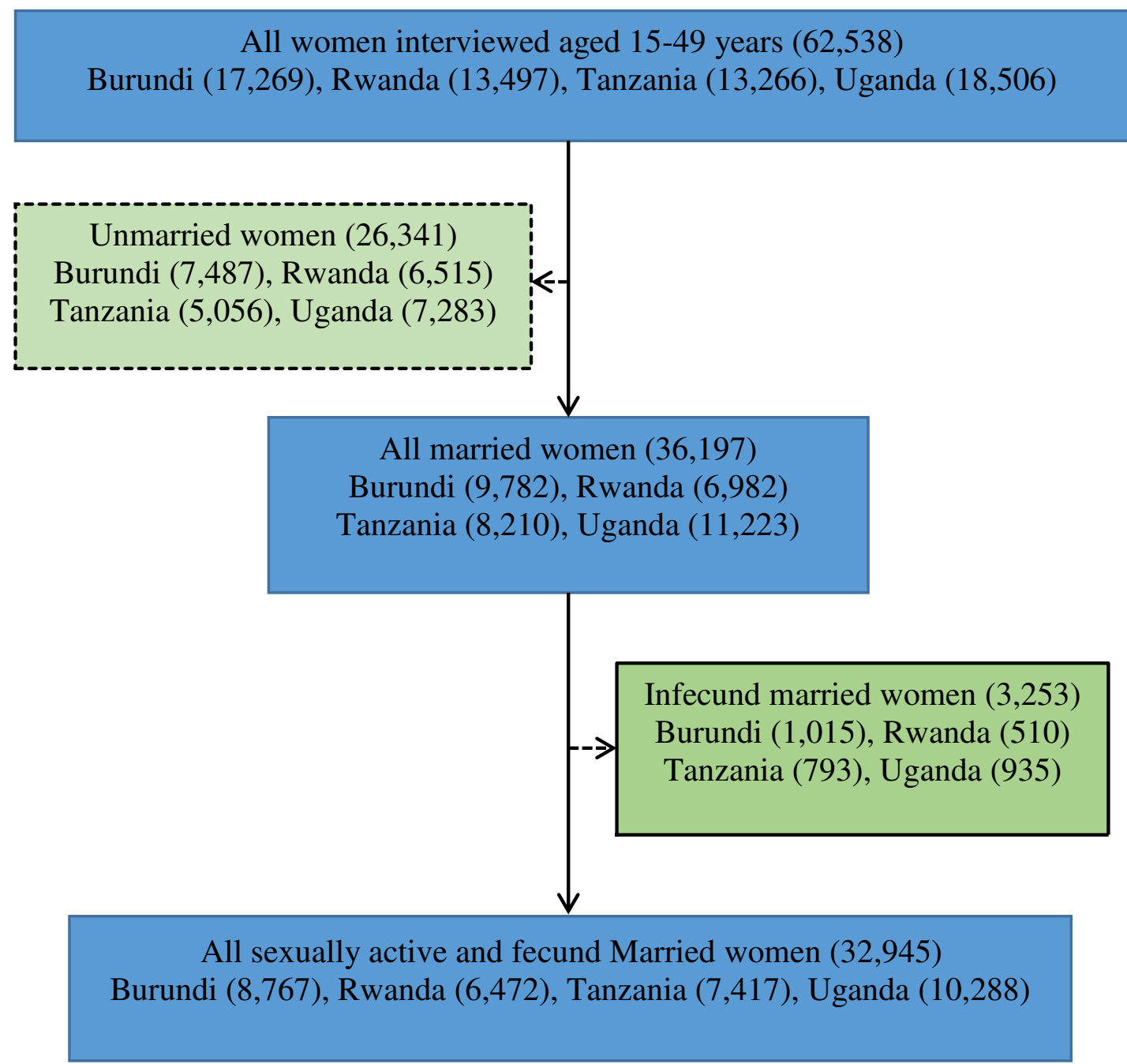

\section{Figure 1: Derivation of the study sample}

\section{Variables and their measurements}

The outcome variable for this study is unmet need for contraception which is binary coded as married women with unmet need for family planning (coded as 1) and married women without unmet need (coded as 0$)$.

We categorized the independent variables into individual and community factors. Individual factors recoded included woman's age (15-24, 25-34, and 35-49); level of education (no education, primary, secondary/higher); wealth index (poor, middle and rich); working status (working and not working); number of living children (0-1, 2-3, 4-5, 6+); husband's desire for children (Both want the same number of children, husband wants more, husbands wants few, don't know); decision-maker on a woman's health care (this is based on a question in the DHS that asks a person who usually decides on respondent's health care) and this was categorized as 
husband/partner alone, respondent alone, joint decision and others; history of child death (yes or no); access to family planning messages (this was measured using four questions that required whether a woman was exposed to family planning messages on radio, television, newspapers and phone in the last month). All the responses to these questions were merged and coded 0 for no exposure to all the media and 1 for those who heard FP messages from any of the four sources.

Community factors included: place of residence (urban, rural); distance to health facility (women were asked if the distance to the health facility was a problem for them to get any medical assistance and responses were coded as: 1 if it was big problem and 0 if it was not a big problem). Other community factors were obtained by aggregation of individual level characteristics of women within their clusters (communities) since the DHS did not directly capture data that could describe these characteristics and the average values at the cluster level used as the cut off point for the categorization. This method of aggregating individual factors is appropriate and has been used in prior studies for the analysis of community factors associated to sexual and reproductive health outcomes [20-26]. This study considers a cluster as a community of women who are likely to share similar or common behaviors, values and norms. In this case, each woman was assigned a value representing the average response of all other respondents in her cluster. These factors included: community education (coded as low for values below the average level of education while high for values equal or above the mean); community wealth (coded as low for values below the mean and high for values equal and above the mean basing on the wealth index categories of the individual women); community women working (coded as low for values below the mean and high for values equal or above the mean); community use of modern contraceptives. Modern contraceptive use was obtained from women's responses on the use of any of the following methods: male or female sterilization, injectable, intrauterine devices, contraceptive pills, implants, female or male condoms, standard days method, lactational amenorrhoea, and emergency contraception. Basing on these responses, we generated a binary variable for modern contraceptive (yes or no) which was later aggregated to generate the cluster level variable of community use of modern contraceptives (coded as high for values equal and above the mean basing on the modern contraceptive variable of the individual women and low for values below the mean). Other community variables included community mean age at first marriage and community mean age at sexual debut which were treated as continuous variables. 


\section{Data analysis}

Data were analyzed in four stages using STATA 15 statistical software. First, we conducted a descriptive summary of the variables using frequency distributions for categorical variables and mean values for continuous variables.

At the second stage; due to the hierarchical nature of the DHS, we applied a bivariate multilevel logistic regression model to examine the crude association between the individual and community-level factors with unmet need for contraception among married women in each of the four countries with the significant level set at $5 \%$.

At the third stage; we pooled all the data for the four countries in order to identify the overall and common individual and community factors associated with unmet need. The pooled sample was a three-level hierarchical structure and therefore, we applied a three-level multivariate mixed-effects logistic regression model with a married woman (at level 1), in a community (at level 2) living in a country (at level 3). At this stage, we ran four models to estimate both the fixed effects and random intercept of between-cluster variation for individual and community level factors. Model 1 was an empty model in order to test the random variability in the intercept, model 2 examined the effect of only the individual woman's characteristics on unmet need for contraception, model 3 examined the effect of only community characteristics and model 4, examined the effect of both individual and community level characteristics concurrently with the results of fixed effects being shown as adjusted odds ratios at $95 \%$ confidence level. The three level random intercept logistic regression model used at this stage can be expressed as:

$$
\log \left[\frac{\pi_{i j k}}{1-\pi_{i j k}}\right]=\boldsymbol{X}^{\prime}{ }_{i j k} \boldsymbol{\beta}+\mu_{j k}+v_{k}
$$

Where: $\pi_{i j k}$ is the probability that the $i^{\text {th }}$ married woman in the $j^{\text {th }}$ community living in the $k^{\text {th }}$ country had unmet need for contraception; $\boldsymbol{\beta}$ is a vector of coefficients to be estimated; $\boldsymbol{X}^{\prime}{ }_{i j k}$ is a vector of individual and community level factors; $\mu_{j k}$ and $v_{k}$ are random effects at community and country level respectively.

The intra-class correlation coefficient (ICC) for each model was calculated to explain the proportion of the between cluster variation in the total variation. The intra-community, $\rho_{\mu}$ and intra-country, $\rho_{v}$, correlation coefficients were obtained from:

$$
\begin{gathered}
\rho_{\mu}=\frac{\sigma^{2}{ }_{\mu}+\sigma^{2}{ }_{v}}{\left(\sigma^{2}{ }_{\mu}+\sigma^{2}{ }^{+}{ }^{+} \pi^{2} / 3\right)} \\
\rho_{v}=\frac{\sigma^{2}{ }_{v}}{\left(\sigma^{2}{ }_{\mu}+\sigma^{2}{ }{ }^{+} \pi^{2} / 3\right)}
\end{gathered}
$$


Where $\sigma_{\mu}^{2}$ is the total variance at community level while $\sigma^{2}{ }_{v}$ the total variance at country level.

The Proportional Change in Variance (PCV) was also computed for each model with respect to the empty model to explain the variability on the odds of unmet need for contraception.

$$
P C V=\left(\frac{V_{e}-V_{i}}{V_{e}}\right)
$$

Where $\mathrm{V}_{\mathrm{e}}$ is variance of unmet need in the empty model and $\mathrm{V}_{i}$ is variance in successive models. At the fourth stage, we assessed the country variations in individual and community level factors associated with unmet need by running a multivariate two-level mixed-effects logistic regression model where married women at level 1 being nested within communities at level 2. The model fitted is represented as:

$$
\log \left[\frac{\pi_{i j}}{1-\pi_{i j}}\right]=\boldsymbol{X}^{\prime}{ }_{i j} \boldsymbol{\beta}+\mu_{j}+\varepsilon_{i j}
$$

Where: $\pi_{i j}$ is the probability that the $i^{\text {th }}$ married woman in the $j^{\text {th }}$ community had unmet need for contraception; $\boldsymbol{\beta}$ is a vector of coefficients to be estimated; $\boldsymbol{X}^{\prime}{ }_{i j}$ is a vector of individual and community level factors; $\mu_{j}$ and $\varepsilon_{i j}$ are random effects at community and individual levels respectively.

We used variance inflation factor (VIF) to check for multi-collinearity among the selected predictor variables in all the four countries, and none of the factors displayed problems in multicollinearity. Still, the log likelihood test and the Akaike Information Criterion (AIC) were used to estimate the goodness of fit of the adjusted final model.

\section{Results}

Table 1 presents the descriptive summary of individual and community characteristics of sexually active and fecund married women who were aged 15-49 years in the four selected countries using their most recent surveys. Married women were nested within 554 clusters (communities) in Burundi, 492 in Rwanda, 608 in Tanzania and 696 in Uganda with the average number of eligible women per community being 15, 13, 12 and 15 in Burundi, Rwanda, Tanzania and Uganda respectively.

In all the countries, majority of the women were residing in rural areas with the highest proportion of them aged 25-34 years, that is; $48 \%$ in Burundi, 50\% in Rwanda, 39\% in Tanzania and $41 \%$ in Uganda. Further, there were more educated women in Uganda than any other country and majority of Burundian women being illiterates (46\%). Relatedly, the proportion of 
women staying in communities with high education and low education were still witnessed in Uganda and Burundi respectively.

In addition, majority of married women in Burundi were staying in poor households (42\%) while Tanzania had the highest proportion of them staying in the highest wealth quintile (43\%). Similarly, results also show that the highest proportion of women in Burundi were staying in communities with high poverty $(62 \%)$.

Overall, at least 8 in 10 married women had more than one child in all the countries while 3 in 10 women in Burundi and Uganda had ever experienced the death of a child. In regard to desire for children, Uganda (32\% versus 10\%) and Tanzania (24\% versus $6 \%$ ) had the highest proportion of husbands whose desire for more children was far much higher than the women's desires. Also, unlike Uganda (4 in 10) at least 6 in 10 married women make joint decisions with their partners regarding their health in other three countries.

Results also show that; not only majority of married women working $88 \%$ in Burundi, $87 \%$ in Rwanda, $80 \%$ in Uganda and $78 \%$ in Tanzania but also were living with their partners. Relatedly, the highest proportion of women staying in communities where women are working was observed in Rwanda (64\%) and Tanzania (63\%).

Regarding access to family planning messages, Ugandan women were more exposed $(71 \%)$, followed by Tanzania (67\%), Rwanda (56\%) and Burundi (32\%). Still, 2 in 5 married women highlighted that the distance to the health facility was a big problem both in Tanzania and Uganda. Also, 5 in 10 married women were living in communities that have low modern contraceptive uptake in all the four countries.

In all the countries, community mean age at sexual debut was lower than that of age at first marriage ranging between 16.5 years in Uganda to 20.5 years in Rwanda. Similarly, the community mean age at marriage was lowest in Uganda (18.3 years) and highest in Rwanda (21.2 years). This shows that women engage in sex much earlier before marriage. On average still, community mean number of living children was at least 3 children in all the countries.

Results in Table 2 indicate that the prevalence of unmet need for contraception among married women ranges between $20 \%$ in Rwanda and 33\% in Burundi. Still, $22 \%$ and $28 \%$ of the married women in Tanzania and Uganda respectively wanted to space or limit child bearing but were not using contraceptives. 
Table 1: Distribution of married women by the selected characteristics

\begin{tabular}{|c|c|c|c|c|c|c|c|c|c|c|}
\hline \multirow[t]{2}{*}{ Selected characteristic } & \multicolumn{2}{|c|}{$\begin{array}{c}2016-2017 \\
\text { Burundi } \\
(\mathrm{N}=8,767)\end{array}$} & \multicolumn{2}{|c|}{$\begin{array}{c}2014-2015 \\
\text { Rwanda } \\
(\mathrm{N}=6,472)\end{array}$} & \multicolumn{2}{|c|}{$\begin{array}{l}2015-2016 \\
\text { Tanzania } \\
(\mathrm{N}=7,417)\end{array}$} & \multicolumn{2}{|c|}{$\begin{array}{c}2016 \\
\text { Uganda } \\
(\mathrm{N}=10,288)\end{array}$} & \multicolumn{2}{|c|}{$\begin{array}{c}2014-2016 \\
\text { Pooled } \\
(\mathrm{N}=32,945)\end{array}$} \\
\hline & $\mathrm{N}$ & $\%$ & $\mathrm{~N}$ & $\%$ & $\mathrm{~N}$ & $\%$ & $\mathrm{~N}$ & $\%$ & $\mathrm{~N}$ & $\%$ \\
\hline \multicolumn{11}{|l|}{ Woman's age } \\
\hline $15-24$ & 1,730 & 19.7 & 961 & 14.9 & 2,123 & 28.6 & 3,258 & 31.7 & 8,073 & 24.5 \\
\hline $25-34$ & 4,219 & 48.1 & 3,211 & 49.6 & 2,854 & 38.5 & 4,202 & 40.8 & 14,486 & 44.0 \\
\hline $35-49$ & 2,818 & 32.2 & 2,300 & 35.5 & 2,440 & 32.9 & 2,828 & 27.5 & 10,386 & 31.5 \\
\hline \multicolumn{11}{|l|}{ Level of education } \\
\hline No education & 4,062 & 46.3 & 994 & 15.4 & 1,356 & 18.3 & 1,075 & 10.4 & 7,487 & 22.7 \\
\hline Primary & 3,709 & 42.3 & 4,616 & 71.3 & 4,888 & 65.9 & 6,137 & 59.7 & 19,350 & 58.7 \\
\hline Secondary/Higher & 996 & 11.4 & 862 & 13.3 & 1,173 & 15.8 & 3,076 & 29.9 & 6,108 & 18.6 \\
\hline \multicolumn{11}{|l|}{ Wealth index } \\
\hline Poor & 3,686 & 42.0 & 2,585 & 40.0 & 2,879 & 38.8 & 4,000 & 38.9 & 13,150 & 40.0 \\
\hline Middle & 1,775 & 20.3 & 1,346 & 20.8 & 1,382 & 18.6 & 2,000 & 19.4 & 6,504 & 19.7 \\
\hline Rich & 3,306 & 37.7 & 2,541 & 39.2 & 3,156 & 42.6 & 4,288 & 41.7 & 13,29 & 40.3 \\
\hline \multicolumn{11}{|c|}{ Number of living children } \\
\hline $0-1$ & 1,534 & 17.5 & 1,464 & 22.6 & 1,919 & 25.9 & 2,219 & 21.6 & 7,135 & 21.7 \\
\hline $2-3$ & 3,113 & 35.5 & 2,603 & 40.2 & 2,644 & 35.6 & 3,378 & 32.8 & 11,738 & 35.6 \\
\hline $4-5$ & 2,460 & 28.1 & 1,643 & 25.4 & 1,623 & 21.9 & 2,488 & 24.2 & 8,215 & 24.9 \\
\hline $6+$ & 1,660 & 18.9 & 762 & 11.8 & 1,231 & 16.6 & 2,203 & 21.4 & 5,857 & 17.8 \\
\hline \multicolumn{11}{|l|}{$\begin{array}{l}\text { Husband's desire for } \\
\text { children }\end{array}$} \\
\hline Both want same & 4,837 & 55.2 & 3,891 & 60.1 & 2,933 & 39.6 & 3,550 & 34.5 & 15,212 & 46.2 \\
\hline Husband wants more & 1,533 & 17.5 & 748 & 11.6 & 1,776 & 23.9 & 3,265 & 31.7 & 7,322 & 22.2 \\
\hline Husband wants fewer & 1,541 & 17.6 & 1,152 & 17.8 & 433 & 5.8 & 1,018 & 9.9 & 4,144 & 12.6 \\
\hline Don't know & 855 & 9.7 & 681 & 10.5 & 2,275 & 30.7 & 2,455 & 23.9 & 6,267 & 19.0 \\
\hline \multicolumn{11}{|l|}{$\begin{array}{l}\text { Decision-maker on a } \\
\text { woman's healthcare }\end{array}$} \\
\hline Husband/partner alone & 2,448 & 27.9 & 1,040 & 16.1 & 2,010 & 27.1 & 2,718 & 26.4 & 8,217 & 24.9 \\
\hline
\end{tabular}




\begin{tabular}{|c|c|c|c|c|c|c|c|c|c|c|}
\hline Respondent alone & 1,006 & 11.5 & 1,468 & 22.7 & 1,140 & 15.4 & 3,031 & 29.5 & 6,6447 & 20.2 \\
\hline Joint decision & 5,297 & 60.4 & 3,927 & 60.7 & 4,236 & 57.1 & 4,499 & 43.7 & 17,959 & 54.5 \\
\hline Others & 16 & 0.2 & 37 & 0.6 & 31 & 0.4 & 40 & 0.4 & 125 & 0.4 \\
\hline \multicolumn{11}{|l|}{ Working status } \\
\hline Not working & 1,070 & 12.2 & 872 & 13.4 & 1,649 & 22.2 & 2,102 & 20.4 & 5,693 & 17.3 \\
\hline Working & 7,697 & 87.8 & 5,600 & 86.6 & 5,768 & 77.8 & 8,186 & 79.6 & 27,252 & 82.7 \\
\hline \multicolumn{11}{|l|}{ Living arrangement } \\
\hline Woman stays with partner & 7,691 & 87.7 & 5,867 & 90.7 & 6,867 & 92.6 & 8,615 & 83.7 & 29,041 & 88.2 \\
\hline Woman stays alone & 1,076 & 12.3 & 605 & 9.3 & 550 & 7.4 & 1,673 & 16.3 & 3,904 & 11.9 \\
\hline \multicolumn{11}{|l|}{ History of child death } \\
\hline $\mathrm{No}^{\dagger}$ & 6,392 & 72.9 & 4,938 & 76.3 & 5,765 & 77.7 & 7,690 & 74.7 & 24,785 & 75.2 \\
\hline Yes & 2,375 & 27.1 & 1,534 & 23.7 & 1,652 & 22.3 & 2,598 & 25.3 & 8,160 & 24.8 \\
\hline \multicolumn{11}{|l|}{$\begin{array}{l}\text { Access to family planning } \\
\text { messages }\end{array}$} \\
\hline No & 5,964 & 68.0 & 2,830 & 43.7 & 2,417 & 32.6 & 3,035 & 29.5 & 14,246 & 43.2 \\
\hline Yes & 2,803 & 32.0 & 3,642 & 56.3 & 5,000 & 67.4 & 7,253 & 70.5 & 18,698 & 56.8 \\
\hline \multicolumn{11}{|l|}{ Place of residence } \\
\hline Urban & 891 & 10.2 & 1,116 & 17.2 & 2,307 & 31.1 & 2,477 & 24.1 & 6,791 & 20.6 \\
\hline Rural & 7,876 & 89.8 & 5,356 & 82.8 & 5,110 & 68.9 & 7,811 & 75.9 & 26,154 & 79.4 \\
\hline \multicolumn{11}{|l|}{$\begin{array}{l}\text { Distance to the health } \\
\text { facility }\end{array}$} \\
\hline No problem & 5,913 & 67.5 & 5,040 & 77.9 & 4,066 & 54.8 & 6,309 & 61.3 & 21,329 & 64.7 \\
\hline Big problem & 2,854 & 32.5 & 1,432 & 22.1 & 3,351 & 45.2 & 3,979 & 38.7 & 11,616 & 35.3 \\
\hline \multicolumn{11}{|l|}{ Community education } \\
\hline Low & 5,694 & 64.9 & 3,601 & 55.6 & 3,828 & 51.6 & 5,237 & 50.9 & 18,360 & 55.7 \\
\hline High & 3,073 & 35.1 & 2,871 & 44.4 & 3,589 & 48.4 & 5,051 & 49.1 & 14,584 & 44.3 \\
\hline \multicolumn{11}{|l|}{ Community wealth } \\
\hline Low & 5,472 & 62.4 & 4,004 & 61.9 & 4,111 & 55.4 & 4,638 & 45.1 & 18,226 & 55.3 \\
\hline High & 3,295 & 37.6 & 2,468 & 38.1 & 3,306 & 44.6 & 5,650 & 54.9 & 14,719 & 44.7 \\
\hline \multicolumn{11}{|c|}{ Community women working } \\
\hline Low & 3,232 & 36.9 & 2,337 & 36.1 & 3,405 & 45.9 & 4,926 & 47.9 & 13,900 & 42.2 \\
\hline High & 5,535 & 63.1 & 4,135 & 63.9 & 4,012 & 54.1 & 5,362 & 52.1 & 19,045 & 57.8 \\
\hline
\end{tabular}




\section{Community use of modern}

\section{contraceptives}

High

$\begin{array}{rrrrrrrrrr}4,268 & 48.7 & 3,348 & 51.7 & 3,935 & 53.1 & 5,404 & 52.5 & 16,956 & 51.5 \\ 4,499 & 51.3 & 3,124 & 48.3 & 3,482 & 46.9 & 4,884 & 47.5 & 15,989 & 48.5 \\ \mathbf{1 9 . 9} & 1.8 & \mathbf{2 1 . 2} & 1.5 & \mathbf{1 8 . 7} & 1.7 & \mathbf{1 8 . 3} & 1.5 & \mathbf{1 9 . 4} & 1.9 \\ \mathbf{1 9 . 4} & 1.6 & \mathbf{2 0 . 5} & 1.4 & \mathbf{1 7 . 0} & 1.5 & \mathbf{1 6 . 5} & 1.1 & \mathbf{1 8 . 2} & 2.2 \\ \mathbf{3 . 6} & 0.7 & \mathbf{3 . 1} & 0.6 & \mathbf{3 . 4} & 0.9 & \mathbf{3 . 7} & 0.8 & \mathbf{3 . 5} & 0.8\end{array}$

Low

Community mean age at marriage

Community mean age at

sexual debut

Community mean number of

living children

$N$ is the weighted frequency, \% is the percentage; in bold in the frequency column is the mean of the continuous variable; in italic in the
percentage column is the standard deviation
percentage column is the standard deviation 
Table 2 shows the distribution of married women with unmet need for contraception in the four countries. The results in Table 2 indicate that the prevalence of unmet need for contraception among married women ranges from $20 \%$ in Rwanda to 33\% in Burundi. Among the four countries, married women in Uganda and Burundi had the highest need for spacing (18\%). Relatedly, Table 2 shows that 15\%,10\%, 9\% and 7\% of the married women in Burundi, Uganda, Rwanda and Tanzania respectively had unmet need for limiting.

Table 2: Prevalence of unmet need for family planning among married women in four East African countries

\begin{tabular}{llrrr}
\hline & Burundi & Rwanda & Tanzania & \multicolumn{1}{c}{ Uganda } \\
Unmet need & $\mathrm{N}(\%)$ & $\mathrm{N}(\%)$ & \multicolumn{1}{c}{$\mathrm{N}(\%)$} & \multicolumn{1}{c}{$\mathrm{N}(\%)$} \\
\hline Unmet need for spacing & $1,574(17.9)$ & $745(11.5)$ & $1,276(15.5)$ & $2,054(18.3)$ \\
Unmet need for limiting & $1,333(15.2)$ & $578(8.9)$ & $540(6.6)$ & $1,129(10.1)$ \\
Total unmet need & $2,907(33.2)$ & $1,323(20.4)$ & $1,816(22.1)$ & $3,183(28.4)$ \\
\hline
\end{tabular}

All estimates based on weighted data

Results in Table 3 show the relationship between total unmet need for contraception and selected characteristics. The results indicate that woman's age, education level, wealth index, number of living children, husband's desire for children, decision-maker on woman's health care, history of child death, access to family planning messages, community education, community use of modern contraceptives, and community mean number of living children were significantly associated with unmet need for contraception in all the four countries. However, decision-maker on woman's health care and the proportion of community women working were only important in Burundi while living arrangement was significant in Rwanda and Tanzania only. Additionally, with the exception of Rwanda, working status of the woman was associated with unmet need for contraception in the other countries. Other significant factors include: place of residence in Burundi, Uganda and the pooled model; distance to health facility in Rwanda, Uganda and the pooled model; community wealth in Burundi, Rwanda, Tanzania, Uganda and the pooled model; community mean age at marriage in Burundi, Tanzania, Uganda and the pooled model; community mean age at sexual debut in Tanzania, Uganda and the pooled model. 
Table 3: Bivariate association of unmet need for contraception among married women in the four East African countries with individual and community characteristics

\begin{tabular}{|c|c|c|c|c|c|}
\hline Selected characteristic & $\begin{array}{l}\text { Burundi } \\
\text { OR }(95 \% \text { CI) }\end{array}$ & $\begin{array}{l}\text { Rwanda } \\
\text { OR }(95 \% \text { CI }) \\
\end{array}$ & $\begin{array}{l}\text { Tanzania } \\
\text { OR }(95 \% \text { CI }) \\
\end{array}$ & $\begin{array}{l}\text { Uganda } \\
\text { OR }(95 \% \text { CI) } \\
\end{array}$ & $\begin{array}{l}\text { Pooled } \\
\text { OR }(95 \% \mathrm{CI}) \\
\end{array}$ \\
\hline \multicolumn{6}{|l|}{ Woman's age } \\
\hline $15-24^{\dagger}$ & 1.00 & 1.00 & 1.00 & 1.00 & 1.00 \\
\hline $25-34$ & $1.60(1.41-1.81)^{* *}$ & $1.67(1.37-2.03) * *$ & $1.07(0.95-1.21)$ & $1.06(0.97-1.17)$ & $1.16(1.09-1.24)^{* *}$ \\
\hline $35-49$ & $2.78(2.45-3.17)^{* *}$ & $2.03(1.66-2.48)^{* *}$ & $1.38(1.22-1.56)^{* *}$ & $1.35(1.22-1.49)^{* *}$ & $1.61(1.50-1.73)^{* *}$ \\
\hline \multicolumn{6}{|l|}{ Level of education } \\
\hline No education $^{\dagger}$ & 1.00 & 1.00 & 1.00 & 1.00 & 1.00 \\
\hline Primary & $0.69(0.63-0.76)^{* *}$ & $0.67(0.57-0.78)^{* *}$ & $0.71(0.63-0.81)^{* *}$ & $0.76(0.67-0.87)^{* *}$ & $0.74(0.69-0.79)^{* *}$ \\
\hline Secondary/Higher & $0.39(0.33-0.45)^{* *}$ & $0.46(0.36-0.58)^{* *}$ & $0.55(0.46-0.65)^{* *}$ & $0.46(0.40-0.53)^{* *}$ & $0.51(0.47-0.55)^{* *}$ \\
\hline \multicolumn{6}{|l|}{ Wealth index } \\
\hline Poor $^{\dagger}$ & 1.00 & 1.00 & 1.00 & 1.00 & 1.00 \\
\hline Middle & $0.89(0.79-0.99) *$ & $0.77(0.66-0.91)^{* *}$ & $0.74(0.65-0.86)^{* *}$ & $0.89(0.79-0.99) *$ & $0.84(0.79-0.90)^{* *}$ \\
\hline Rich & $0.89(0.80-0.98)^{*}$ & $0.76(0.66-0.87)^{* *}$ & $0.50(0.44-0.58)^{* *}$ & $0.59(0.53-0.65)^{* *}$ & $0.68(0.64-0.72)^{* *}$ \\
\hline \multicolumn{6}{|c|}{ Number of living children } \\
\hline $0-1^{\dagger}$ & 1.00 & 1.00 & 1.00 & 1.00 & 1.00 \\
\hline $2-3$ & $2.05(1.77-2.38) * *$ & $1.90(1.58-2.28)^{* *}$ & $1.57(1.38-1.78)^{* *}$ & $1.43(1.27-1.60)^{* *}$ & $1.53(1.41-1.65)^{* *}$ \\
\hline $4-5$ & $3.45(2.97-4.01)^{* *}$ & $2.61(2.16-3.16)^{* *}$ & $1.86(1.61-2.14)^{* *}$ & $1.72(1.52-1.94)^{* *}$ & $2.03(1.87-2.19)^{* *}$ \\
\hline $6+$ & $6.52(5.56-7.67)^{* *}$ & $3.49(2.81-4.35)^{* *}$ & $2.81(2.42-3.28)^{* *}$ & $2.22(1.96-2.51)^{* *}$ & $3.16(2.19-3.43)^{* *}$ \\
\hline \multicolumn{6}{|c|}{ Husband's desire for children } \\
\hline Both want same $^{\dagger}$ & 1.00 & 1.00 & 1.00 & 1.00 & 1.00 \\
\hline Husband wants more & $1.70(1.52-1.91)^{* *}$ & $1.38(1.15-1.66)^{* *}$ & $1.62(1.43-1.82)^{* *}$ & $1.17(1.06-1.30)^{* *}$ & $1.39(1.30-1.48)^{* *}$ \\
\hline Husband wants fewer & $1.27(1.13-1.43) * *$ & $1.12(0.95-1.32)$ & $1.35(1.10-1.66)^{* *}$ & $0.99(0.85-1.14)$ & $1.09(1.00-1.18)^{*}$ \\
\hline Don't know & $1.59(1.37-1.84)^{* *}$ & $1.34(1.11-1.62)^{* *}$ & $0.98(0.87-1.10)$ & $0.98(0.88-1.09)$ & $1.17(1.09-1.26)^{* *}$ \\
\hline \multicolumn{6}{|c|}{$\begin{array}{l}\text { Decision-maker on a woman's } \\
\text { healthcare }\end{array}$} \\
\hline Husband/partner alone ${ }^{\dagger}$ & 1.00 & 1.00 & 1.00 & 1.00 & 1.00 \\
\hline Respondent alone & $1.37(1.19-1.58)^{* *}$ & $1.10(0.92-1.33)$ & $1.16(1.00-1.34)$ & $0.96(0.87-1.07)$ & $1.07(0.99-1.15)$ \\
\hline Joint decision & $0.98(0.88-1.08)$ & $0.82(0.70-0.97)^{*}$ & $0.80(0.72-0.89)^{* *}$ & $0.80(0.73-0.89)^{* *}$ & $0.87(0.81-0.92)^{* *}$ \\
\hline
\end{tabular}




\section{Others}

\section{Working status}

Not working ${ }^{\dagger}$

Working

Living arrangement

Woman stays with partner ${ }^{\dagger}$

Woman stays alone

History of child death

$\mathrm{No}^{\dagger}$

Yes

Access to family planning

messages

$\mathrm{No}^{\dagger}$

Yes

Place of residence

Urban $^{\dagger}$

Rural

Distance to the health facility

No problem ${ }^{\dagger}$

Big problem

\section{Community education}

Low $^{\dagger}$

High

Community wealth

Low $^{\dagger}$

High

Community women working

Low $^{\dagger}$

High

Community use of modern contraceptives

$\mathrm{High}^{\dagger}$

\section{$2.02(0.80-5.14)$}

$0.77(0.11-5.31)$

0.41(0.16-1.02)

$1.36(0.70-2.63)$

$0.86(0.54-1.35)$

1.00

1.00

1.00

$0.75(0.67-0.84)^{* *}$

1.00

$0.90(0.82-0.99) *$

1.00

$1.28(1.11-1.47) * * \quad 0.88(0.74-1.04)$

1.00

$1.14(1.00-1.31)$

1.00

$2.00(1.70-2.36) * *$

1.00

1.00

$1.54(1.40-1.69) * *$

1.00

1.00

1.11(0.99-1.23)

1.00

$1.30(1.20-1.40) * *$

.00

$1.25(1.14-1.36) * *$

1.00

$1.32(1.25-1.40) * *$

$\begin{array}{lllll}1.00 & 1.00 & 1.00 & 1.00 & 1.00 \\ 0.84(0.77-0.92) * * & 0.67(0.59-0.75) * * & 0.74(0.67-0.82) * * & 0.89(0.82-0.97) * & 0.79(0.75-0.83) * *\end{array}$

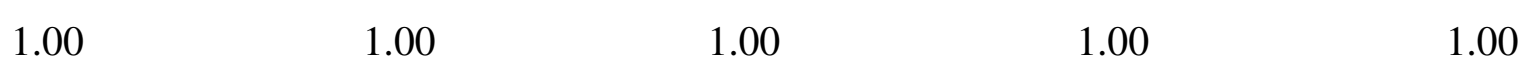

$1.64(1.32-2.05) * * \quad 1.14(0.92-1.40) \quad 1.17(1.00-1.38) \quad 1.60(1.40-1.83) * * \quad 1.39(1.29-1.51)^{* *}$

$1.00 \quad 1.00 \quad 1.00 \quad 1.00$

$1.08(0.98-1.19) \quad 1.29(1.11-1.49) * * \quad 0.95(0.86-1.05) \quad 1.38(1.26-1.50)^{* *} \quad 1.17(1.11-1.24) * *$

$\begin{array}{llll}1.00 & 1.00 & 1.00 & 1.00\end{array}$

$0.85(0.74-0.96) * \quad 0.78(0.67-0.91) * * \quad 0.64(0.55-0.74) * * \quad 0.58(0.52-0.66) * * \quad 0.72(0.67-0.77)^{* *}$

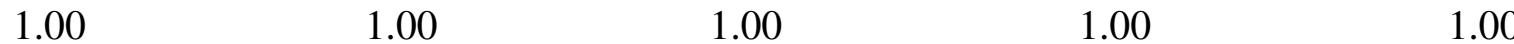

$\begin{array}{lllll}1.10(0.96-1.24) & 0.75(0.64-0.88) * * & 0.66(0.57-0.76) * * & 0.55(0.49-0.61) * * & 0.74(0.69-0.78) * *\end{array}$

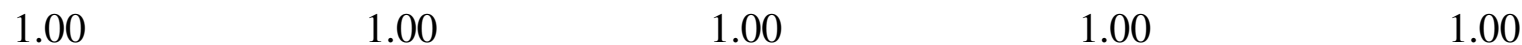

$1.18(1.03-1.34) * \quad 1.08(0.92-1.26) \quad 0.95(0.82-1.10) \quad 1.11(0.98-1.25) \quad 1.06(0.99-1.13)$

$1.00 \quad 1.00$

1.00

1.00

1.00 
Low

Community mean age at

marriage

Community mean age at sexual

debut

Community mean number of

living children

+ is a Reference category, * Significant multilevel logistic regression model. $\begin{array}{lllll}2.05(1.83-2.29)^{* *} & 2.36(2.06-2.69) * * & 2.62(2.29-2.98)^{* *} & 2.36(2.13-2.61)^{* *} & 2.28(2.16-2.41)^{* *} \\ 0.96(0.92-1.00)^{*} & 0.98(0.93-1.03) & 0.91(0.88-0.95)^{* *} & 0.89(0.85-0.92)^{* *} & 0.93(0.91-0.95)^{* *}\end{array}$

$1.60(1.48-1.73)^{* *} \quad 1.32(1.17-1.48)^{* *} \quad 1.41(1.30-1.53)^{* *} \quad 1.31(1.23-1.40)^{* *} \quad 1.42(1.36-1.47)^{* *}$ 
The multivariate multilevel analysis of factors associated with unmet need for contraception among married women in Burundi, Rwanda, Tanzania and Uganda are respectively presented in Tables 5, 6, 7 and 8 while Table 4 presents the pooled analysis for the four countries. The results of the empty models (Model 1) showed that there was a statistically significant variability $(p$-value $=0.000)$ in the odds of unmet need for contraception among married women between communities $(\tau=0.49)$ for the pooled data and $(\tau=0.29,0.2,0.49$ and 0.35$)$ for Burundi, Rwanda, Tanzania and Uganda respectively. In the empty models, the proportion of the variance (ICC) attributed to community level factors is $12.9 \%$ for Tanzania, $9.7 \%$ for Uganda, $8.0 \%$ for Burundi and $7.4 \%$ for Rwanda. Similarly, the ICC in the empty model indicated that $8.7 \%$ and $2.2 \%$ of the total variance in the unmet need for contraception was attributed to differences between communities and to differences within countries respectively in the pooled sample.

In the individual adjusted model (Model 2), similar ICC value (7.1\%) was displayed for Burundi and Rwanda, while Uganda showed $7.4 \%$ and Tanzania displayed the highest (10.6\%). The results further show that $3.8 \%, 13.8 \%, 20.4 \%$ and $25.7 \%$ of the variance in unmet need for contraception across communities was explained by individual characteristics in Rwanda, Burundi, Tanzania and Uganda respectively. In the pooled sample, Model 2 account for $6.5 \%$ of community variance and only $1.6 \%$ of country variance while $25.0 \%$ and $50.0 \%$ of the variance in unmet need for contraception across communities and countries respectively was explained by the individual characteristics. The results in this model further revealed that woman's age, level of education, wealth index, number of living children, husband's desire for children, decision on woman's health care, living arrangements, experienced death of a child, work status and access to family planning messages were significantly associated with unmet need in at least one of the countries while all these factors were very important in the pooled model.

In the community adjusted model (Model 3), only community level variables were considered. The results show that place of residence, distance to the health facility, community education, community wealth, community women working, community use of modern contraceptives, community mean age at marriage, community mean age at sexual debut and community mean number of living children were associated with unmet need for contraception among married women in at least one of the countries or in the pooled sample. The ICC in this model implied that differences between communities account for $2.0 \%, 3.1 \%, 3.4 \%$ and $5.4 \%$ and the corresponding PCV of $73.1 \%, 65.5 \%, 65.7 \%$ and $61.2 \%$ of the variation in unmet need for contraception in Rwanda, Burundi, Uganda and Tanzania respectively. 
Model 4 included both individual and community level factors and the variation in the odds of unmet need for contraception between communities remained statistically significant $(\tau=0.49)$ for the pooled data and $(\tau=0.29,0.26,0.49$ and 0.35$)$ for Burundi, Rwanda, Tanzania and Uganda respectively. In relation to the pooled data, unmet need between communities $(\tau=$ $0.49)$ and the one between countries $(\tau=0.08)$ still remained significant. In this model, the ICC attributed to community level factors is $3.9 \%$ for Burundi, $3.7 \%$ for Uganda, 3.6\% for Tanzania and $2.4 \%$ for Rwanda. Their corresponding proportional change in variance (PCV) respectively indicated that, $55.2 \%, 68.6 \%, 75.5 \%$ and $69.2 \%$ of the variation in unmet need was explained by both individual and community level factors. Further, the pooled model showed that $2.1 \%$ of the community level variance and $1.0 \%$ of the country variance while $83.3 \%$ and $62.5 \%$ indicated the variation in unmet need for contraception across communities and countries respectively that was explained by both individual and community characteristics. For both the pooled data and the individual countries, the combined models of individual-level and community-level factors (Model 4) were preferred in predicting the factors associated with unmet need for contraception among married women because of their smallest values regarding the Akaike information criteria in relation to other models.

Factors associated with unmet need for contraception among married women in four East African countries

The pooled results in Table 4, shows that after controlling for both individual and community factors, married women aged 25-34 $(a O R=0.74,95 \% C I=0.68-0.80)$ and those aged 35-49 years $(a O R=0.68,95 \% C I=0.61-0.75)$ were less likely to have unmet need for contraception compared to those less than 25 years.

The results also indicate that married women with primary education $(a O R=0.93$, $95 \% C I=0.87-0.99)$ and those with secondary/higher education $(a O R=0.88,95 \% C I=0.80-0.97)$ had reduced odds of unmet need for contraception compared to women who had no education. Married women from middle $(a O R=0.89,95 \% C I=0.83-0.96)$ and rich households $(a O R=0.83$, 95\%CI $=0.77-0.89$ ) had lower odds of unmet need compared to those from poor households.

Regarding the number of living children, married women with 2-3 $(a O R=1.73$, 95\% CI=1.591.89), 4-5( $a O R=2.44,95 \% C I=2.20-2.70)$ and more than 5 children $(a O R=3.72,95 \% C I=3.30$ 4.20) were more likely to have unmet need for contraception as compared to those with $0-1$ child.

Similarly, married women whose husbands desire more children $(a O R=1.18,95 \% C I=1.10$ 1.26) were more likely to experience unmet need as compared to women who had the same desire with their partners. 
The findings also indicate that, compared to those who were not working, married women who were working $(a O R=0.89,95 \% C I=0.82-0.95)$ were less likely to experience unmet need for contraception.

Married women who could make independent decisions regarding their own health $(a O R=0.90,95 \% C I=0.85-0.96)$ had reduced odds of unmet need for contraception compared to those whose decisions-maker regarding their health were made entirely by their partners.

The results also indicate that married women who do not stay with their partners $(a O R=1.38$, $95 \% C I=1.23-1.44)$ and those who have ever experience a death of a child $(a O R=1.08$, 95\%CI=1.01-1.15) were significantly associated with increased odds of unmet need for contraception.

Regarding to the influence of the community, unlike married women in urban areas, those staying in rural areas $(a O R=0.86,95 \% C I=0.79-0.93)$ were less likely to have unmet need for contraception.

Further, married women living in communities with low modern contraceptive use $(a O R=2.12$, 95\% $C I=2.00-2.24)$ and those in communities with higher mean number of living children $(a O R=1.13,95 \% C I=1.09-1.18)$ were associated with higher odds for unmet need for contraception. Conversely, married women living in communities with higher age at sexual debut $(a O R=0.97,95 \% C I=0.94-1.00)$ were associated with lower odds for modern contraceptives.

Table 4: Pooled Multilevel analysis of the association between individual and community factors with unmet need among married women in the four East African countries

\begin{tabular}{|c|c|c|c|c|}
\hline Selected characteristic & Model 1 & $\begin{array}{l}\text { Model } 2 \\
\text { aOR }(95 \% \mathrm{CI})\end{array}$ & $\begin{array}{l}\text { Model } 3 \\
\text { aOR }(95 \% \mathrm{CI})\end{array}$ & $\begin{array}{l}\text { Model } 4 \\
\text { aOR }(95 \% \text { CI })\end{array}$ \\
\hline \multicolumn{5}{|l|}{ Fixed effects } \\
\hline \multicolumn{5}{|l|}{ Woman's age } \\
\hline $15-24^{\dagger}$ & & 1.00 & & 1.00 \\
\hline $25-34$ & & $0.73(0.66-0.78)^{* *}$ & & $0.74(0.68-0.80)^{* *}$ \\
\hline $35-49$ & & $0.63(0.57-0.70)^{* *}$ & & $0.68(0.61-0.75)^{* *}$ \\
\hline \multicolumn{5}{|l|}{ Level of education } \\
\hline No education $^{\dagger}$ & & 1.00 & & 1.00 \\
\hline Primary & & $0.89(0.83-0.95)^{* *}$ & & $0.93(0.87-0.99)^{*}$ \\
\hline Secondary/Higher & & $0.84(0.76-0.93)^{* *}$ & & $0.88(0.80-0.97)^{* *}$ \\
\hline Wealth index & & & & \\
\hline
\end{tabular}


Poor $^{\dagger}$

Middle

Rich

Number of living children

$0-1^{\dagger}$

2-3

4-5

$6+$

Husband's desire for

children

Both want same ${ }^{\dagger}$

Husband wants more

Husband wants fewer

Don't know

Decision-maker on a

woman's healthcare

Husband/partner alone ${ }^{\dagger}$

Respondent alone

Joint decision

Others

Working status

Not working ${ }^{\dagger}$

Working

Living arrangement

Woman stays with partner ${ }^{\dagger}$

Woman stays alone

History of child death

$\mathrm{No}^{\dagger}$

Yes

Access to family planning messages

$\mathrm{No}^{\dagger}$

Yes

Place of residence

Urban $^{\dagger}$

Rural

Distance to the health facility

No problem ${ }^{\dagger}$

Big problem

Community education

Low $^{\dagger}$

High

Community wealth

Low $^{\dagger}$

High

Community women working

Low $^{\dagger}$

High

Community use of modern contraceptives
1.00

1.00

$0.86(0.80-0.92)^{* *}$

$0.77(0.72-0.82)^{* *}$

1.00

$1.75(1.61-1.91)^{* *}$

$2.55(2.31-2.83)^{* * *}$

$4.20(3.73-4.72)^{* *}$

1.00

$1.20(1.13-1.29)^{* *}$

$1.06(0.97-1.15)$

1.03(0.96-1.11)

1.00

$0.99(0.92-1.07)$

$0.91(0.84-0.96)^{* *}$

1.02(0.64-1.61)

1.00

$0.88(0.82-0.94)^{* *}$

1.00

$1.38(1.27-1.46)^{* *}$

1.00

$1.07(1.01-1.14)^{*}$

1.00

$0.87(0.83-0.92)^{* *}$

1.00

$0.91(0.84-0.98) *$

1.00

$1.00(0.92-1.08)$

$0.90(0.85-0.96) * *$

$0.95(0.60-1.50)$

1.00

$0.89(0.82-0.95)^{* *}$

1.00

$1.33(1.23-1.44)^{* *}$

1.00

$1.08(1.01-1.15)^{*}$

1.00

$0.89(0.84-0.94)$

$1.00 \quad 1.00$

$1.07(1.01-1.12)^{*} \quad 1.02(0.97-1.08)$

$1.00 \quad 1.00$

$1.02(0.95-1.09) \quad 1.06(0.98-1.14)$

$1.00 \quad 1.00$

$0.91(0.85-0.97) * * \quad 0.99(0.92-1.07)$

$1.00 \quad 1.00$

$1.01(0.96-1.07) \quad 1.05(0.99-1.12)$ 
$\operatorname{High}^{\dagger}$

Low

Community mean age at

marriage

Community mean age at sexual

debut

Community mean number of

living children

Random effect

Country level

Variance (SE)

$\operatorname{ICC}(\%)$

$\operatorname{PCV}(\%)$

Community level

Variance (SE)

$\operatorname{ICC}(\%)$

$\operatorname{PCV}(\%)$

Model fit statistics

Log likelihood

AIC

Sample size

Country level

Community level

Individual level
1.00

$2.11(2.00-2.23) * *$
$1.01(0.98-1.04)$

1.00

$2.12(2.00-2.24) * *$

1.03(1.00-1.06)

$0.97(0.94-1.00)^{*} \quad 0.97(0.94-1.00)^{*}$

$1.30(1.25-1.35)^{* *} \quad 1.13(1.09-1.18)^{* *}$
$0.04(0.03) * *$
1.1
50.0

$0.03(0.01)^{* *}$

2.0

87.5

25.0

$-19,236$

4

2,350

32,684
$-18,575$

37,193

$-18,727$

37,478

\section{4}

2,350

32,684

4
2,350
32,684

$$
\begin{gathered}
0.03(0.02)^{* *} \\
1.0 \\
62.5
\end{gathered}
$$

$0.04(0.01)^{* *}$

2.1

83.3

$-18,228$

36,518

4

2,350

32,684

$\dagger$ is a Reference category, * Significant at $p<0.05, * *$ significant at $p<0.01 ;$ aOR is the adjusted odds ratio; the assessment was based on multivariate-multilevel logistic regression model.

Factors associated with unmet need among married women in the individual countries Results in Table 5, 6, 7 and 8 revealed several individual and community-level factors that are associated with unmet need for contraception in each of the four countries. Number of living children, husband's desire for children and living arrangement were some of the most significant factors that influence unmet need for contraception across all the four countries.

Married women with 2-3, 4-5 and 6+ children were more likely to have unmet need for contraception compared to those with 0-1 living child. The results indicate that the odds of having unmet need for contraception were respectively $(a O R=2.14,95 \% C I=1.81-2.52$; $a O R=3.60, \quad 95 \% C I=2.98-4.35 ; \quad a O R=6.43,95 \% C I=5.18-7.99)$ in Burundi, $(a O R=1.91$, $95 \% C I=1.55-2.35 ; a O R=2.79,95 \% C I=2.18-3.57 ; a O R=4.05,95 \% C I=3.00-5.45)$ in Rwanda, $(a O R=1.90,95 \% C I=1.59-2.28 ; \quad a O R=2.49, \quad 95 \% C I=1.97-3.15 ; \quad a O R=3.74,95 \% C I=2.86-$ $4.89)$ in Tanzania and $(a O R=1.61,95 \% C I=1.42-1.83 ; \quad a O R=2.04,95 \% C I=1.74-2.40$; $a O R=2.54,95 \% C I=2.10-3.07)$ in Uganda. 
Results still revealed that the likelihood of occurrence of unmet need for contraception was high among married women who were not staying with their partners compared to those who were staying together $(a O R=1.25,95 \% C I=1.08-1.45)$ in Burundi, $(a O R=2.29,95 \% C I=1.87$ 2.80) in Rwanda, $(a O R=1.45,95 \% C I=1.17-1.79)$ in Tanzania and $(a O R=1.15,95 \% C I=1.03$ 1.29) in Uganda.

Further, results also indicate that women whose partners had a higher desire for children had $(a O R=1.45,95 \% C I=1.29-1.64)$ in Burundi, $(a O R=1.24,95 \% C I=1.03-1.50)$ in Rwanda and $(a O R=1.17,95 \% C I=1.01-1.35)$ in Tanzania increased odds of unmet compared to their counterparts who shared the number of desired children with their partners. Additionally, married women in Burundi who had a higher desire for desired children as compared to their partners $(a O R=1.22,95 \% C I=1.08-1.37)$ and those who did not know their partners number of desired children $(a O R=1.44,95 \% C I=1.24-1.68)$ were more likely to experience unmet need for family planning. On contrary, married women in Uganda who did not know their partners' number of desired children were $(a O R=0.89,95 \% C I=0.80-1.00)$ less likely to experience unmet need for family planning as compared to those who shared the same number of desired children.

In Burundi, Tanzania and Uganda, older women were less likely to experience unmet need for contraceptives as compared to the young ones. Specifically, Burundian married women aged 25-34 had $(a O R=0.80,95 \% C I=0.69-0.93)$, those aged 35-49 had $(a O R=0.75,95 \% C I=0.63-$ $0.91)$; in Tanzania, those aged 25-34 had $(a O R=0.71,95 \% C I=0.80-1.00)$, those aged 35-49 had $(a O R=0.62,95 \% C I=0.49-0.77)$ and Ugandan women aged 25-34 had $(a O R=0.77$, $95 \% C I=0.68-0.87)$ and those aged 35-49 had $(a O R=0.75,95 \% C I=0.64-0.88)$ reduced odds of unmet need for contraception.

Relatedly, compared to the poor, married women in Burundi from a middle wealth quantile $(a O R=0.84,95 \% C I=0.75-0.95)$ and the rich both in Tanzania $(a O R=0.66,95 \% C I=0.53-0.82)$ and Uganda $(a O R=0.86,95 \% C I=0.76-0.97)$ were less likely to have unmet need for contraception.

Further, unlike Tanzania, educated married women were less likely to have unmet need. Burundian, and Rwandan women with primary education respectively had $(a O R=0.81$, $95 \% C I=0.73-0.89 ; a O R=0.84,95 \% C I=0.71-0.99)$ reduced odds whereas the odds for those with secondary/higher education were $(a O R=0.64, \quad 95 \% C I=0.53-0.78 ; \quad a O R=0.71$, $95 \% C I=0.54-0.94 ; \quad a O R=0.76,95 \% C I=0.64-0.90)$ in Burundi, Rwanda and Uganda respectively. 
Decision on woman's health care was also found to be a key determinant of unmet need for contraception in Burundi and Uganda. Married women whose decisions on their health were made by other people other than the couple $(a O R=3.07,95 \% C I=1.15-8.19)$ had increased odds while women in Uganda who make joint decision with their partners had $(a O R=0.83$, 95\% CI $=0.75-0.91)$ reduced odds of unmet need as compared to women whose decision concerning their health are entirely made by their partners.

Results still indicate that married women who were working in Rwanda, Tanzania and Uganda were respectively $(a O R=0.79,95 \% C I=0.65-0.96),(a O R=0.69,95 \% C I=0.59-0.80)$ and $(a O R=0.85,95 \% C I=0.77-0.94)$ less likely to experience unmet need for contraception respectively compared to married women who were not working at the time of the survey.

The risk of unmet need for contraception was also high among married women in Burundi who had a history of child death compared to those with no child death history $(a O R=1.17$, $95 \% C I=1.05-1.29)$.

Married women who had access to family planning messages in Burundi and Rwanda were respectively $(a O R=0.87,95 \% C I=0.79-0.96)$ and $(a O R=0.75,95 \% C I=0.66-0.85)$ less likely to have unmet need for contraception as compared to those who had no access.

Regarding community effect, results show that community use of modern contraceptives was consistently associated with unmet need for contraception in all the four countries. Unlike women living in communities with high uptake of modern contraceptives, married women living in a community with low proportion of women using modern contraceptives were twice more likely to experience unmet need for contraception in Burundi $(a O R=1.86,95 \% C I=1.66$ 2.09) in Rwanda ( $a O R=2.32$, 95\% CI=2.02-2.66), in Tanzania $(a O R=2.33,95 \% C I=2.02-2.69)$ and in Uganda $(a O R=2.14,95 \% C I=1.92-2.37)$.

In regard to community mean number of living children, results show that married women in communities with higher number of living children in Burundi and Tanzania had $(a O R=1.16$, $95 \% C I=1.06-1.26)$ and $(a O R=1.22,95 \% C I=1.12-1.34)$ respectively higher odds of unmet need compared to that married women in communities with lower number of living children. Married women in Uganda who highlighted that the distance to the health facility was a big problem were more likely to report unmet need for contraception $(a O R=1.17,95 \% C I=1.07$ 1.27).

In Tanzania, married women in communities with higher age at marriage $(a O R=1.09$, $95 \% C I=1.02-1.16)$ were more likely to experience unmet need for contraception as compared to those staying in communities with low community age at marriage. 
Further, a higher community wealth was associated with lower odds of unmet need for family planning among married women in Uganda $(a O R=0.86,95 \% C I=0.75-0.99)$.

In Tanzania and Uganda, married women living in communities with higher age at sexual debut were respectively $(a O R=0.90,95 \% C I=0.84-0.97)$ and $(a O R=0.92,95 \% C I=0.86-0.98)$ less likely to experience unmet for family planning. Similarly, married women staying in rural areas were also less likely to report unmet need for contraception both in Tanzania $(a O R=0.73$, $95 \% C I=0.59-0.90)$ and Uganda $(a O R=0.84,95 \% C I=0.73-0.97)$ as compared to their counterparts in urban.

With regards to community mean age at sexual debut, married women in Tanzania (AOR= $0.90,95 \% \mathrm{CI}=0.83-0.98)$ and those in Uganda $(\mathrm{AOR}=0.91,95 \% \mathrm{CI}=0.84-0.98)$ living in communities with high age at sexual debut were significantly associated with reduced odds of unmet need for family planning.

Table 5: Multilevel analysis of the association between individual and community factors with unmet need among married women in Burundi

\begin{tabular}{|c|c|c|c|c|}
\hline Selected characteristic & Model 1 & $\begin{array}{l}\text { Model } 2 \\
\text { aOR }(95 \% \mathrm{CI})\end{array}$ & $\begin{array}{l}\text { Model } 3 \\
\text { aOR }(95 \% \mathrm{CI})\end{array}$ & $\begin{array}{l}\text { Model } 4 \\
\text { aOR }(95 \% \mathrm{CI})\end{array}$ \\
\hline \multicolumn{5}{|l|}{ Fixed effects } \\
\hline \multicolumn{5}{|l|}{ Woman's age } \\
\hline $15-24^{\dagger}$ & & 1.00 & & 1.00 \\
\hline $25-34$ & & $0.81(0.70-0.94)^{* *}$ & & $0.80(0.69-0.93)^{* *}$ \\
\hline $35-49$ & & $0.75(0.62-0.90) * *$ & & $0.75(0.63-0.91)^{* *}$ \\
\hline \multicolumn{5}{|l|}{ Level of education } \\
\hline No education $^{\dagger}$ & & 1.00 & & 1.00 \\
\hline Primary & & $0.81(0.74-0.89)^{* *}$ & & $0.81(0.73-0.89)^{* *}$ \\
\hline Secondary/Higher & & $0.63(0.53-0.76)^{* *}$ & & $0.64(0.53-0.78) * *$ \\
\hline \multicolumn{5}{|l|}{ Wealth index } \\
\hline Poor $^{\dagger}$ & & 1.00 & & 1.00 \\
\hline Middle & & $0.87(0.77-0.98)^{*}$ & & $0.84(0.75-0.95)^{* *}$ \\
\hline Rich & & 0.94(0.84-1.06) & & $0.90(0.80-1.01)$ \\
\hline \multicolumn{5}{|c|}{ Number of living children } \\
\hline $0-1^{\dagger}$ & & 1.00 & & 1.00 \\
\hline $2-3$ & & $2.15(1.82-2.54) * *$ & & $2.14(1.81-2.52)^{* *}$ \\
\hline $4-5$ & & $3.69(3.05-4.46)^{* *}$ & & $3.60(2.98-4.35)^{* *}$ \\
\hline $6+$ & & $7.01(5.65-8.68)^{* *}$ & & $6.43(5.18-7.99) * *$ \\
\hline \multicolumn{5}{|l|}{$\begin{array}{l}\text { Husband's desire for } \\
\text { children }\end{array}$} \\
\hline Both want same ${ }^{\dagger}$ & & 1.00 & & 1.00 \\
\hline Husband wants more & & $1.47(1.31-1.66)^{* *}$ & & $1.45(1.29-1.64) * *$ \\
\hline Husband wants fewer & & $1.24(1.10-1.39)^{* *}$ & & $1.22(1.08-1.37) * *$ \\
\hline Don't know & & $1.40(1.20-1.63)^{* *}$ & & $1.44(1.24-1.68) * *$ \\
\hline
\end{tabular}




\section{Decision-maker on a}

woman's healthcare

Husband/partner alone ${ }^{\dagger}$
1.00

$1.09(0.93-1.28)$

$1.02(0.92-1.13)$

2.96(1.10-7.98)*

1.00

$1.15(0.99-1.33)$

1.00

$1.31(1.14-1.52)^{* *}$

1.00

$1.15(1.04-1.27)^{* *}$

1.00

$0.88(0.80-0.97)^{* *}$
1.00

$1.11(0.95-1.30)$

$1.00(0.90-1.11)$

$3.07(1.15-8.19)^{*}$

1.00

1.13(0.97-1.32)

1.00

$1.25(1.08-1.45)^{* *}$

1.00

$1.17(1.05-1.29)^{* *}$

Access to family planning messages

$\mathrm{No}^{\dagger}$

Yes

Place of residence

Urban $^{\dagger}$

Rural

Distance to the health

facility

No problem ${ }^{\dagger}$

Big problem

Community education

Low $^{\dagger}$

High

Community wealth

Low $^{\dagger}$

High

Community women

working

Low $^{\dagger}$

High

Community use of modern

contraceptives

$\mathrm{High}^{\dagger}$

Low

Community mean age at

marriage

Community mean age at

sexual debut

Community mean number

of living children

\section{Random effect}

Community level variance (SE)

$\operatorname{ICC}(\%)$
8.0

1.00

$1.20(0.94-1.53)$

1.00

$0.87(0.79-0.96)^{* *}$

1.00

$1.07(0.82-1.40)$

$1.00 \quad 1.00$

$1.00(0.91-1.10) \quad 0.99(0.90-1.10)$

$1.00 \quad 1.00$

$1.06(0.92-1.22) \quad 1.15(0.99-1.34)$

$1.00 \quad 1.00$

$1.04(0.91-1.19) \quad 1.09(0.94-1.27)$

$1.00 \quad 1.00$

$1.01(0.90-1.14) \quad 0.98(0.86-1.12)$

$\begin{array}{ll}1.00 & 1.00 \\ 1.75(1.57-1.94)^{* *} & 1.86(1.66-2.09)^{* *} \\ 0.99(0.91-1.07) & 1.01(0.92-1.10) \\ & \\ 0.99(0.91-1.08) & 1.01(0.92-1.10) \\ & \\ 1.40(1.29-1.52)^{* *} & 1.16(1.06-1.26)^{* *}\end{array}$

$0.29(0.03)^{* *} \quad 0.25(0.03)^{* *}$

$0.10(0.02)^{* *}$

$0.13(0.02)^{* *}$

3.1 
PCV $(\%)$

Model fit statistics

Log likelihood

AIC
13.8

65.5

55.2

$-6,278$ 12,615

$\dagger$ is a Reference category, ${ }^{*}$ Significant at $p<0.05,{ }^{* *}$ significant at $p<0.01 ;$ aOR is the adjusted odds ratio; the assessment was based on multivariate-multilevel logistic regression model.

Table 6: Multilevel analysis of the association between individual and community factors with unmet need among married women in Rwanda

\begin{tabular}{|c|c|c|c|c|}
\hline Selected characteristic & Model 1 & $\begin{array}{l}\text { Model } 2 \\
\operatorname{aOR}(95 \% \mathrm{CI})\end{array}$ & $\begin{array}{l}\text { Model } 3 \\
\text { aOR }(95 \% \mathrm{CI})\end{array}$ & $\begin{array}{l}\text { Model } 4 \\
\operatorname{aOR}(95 \% \mathrm{CI})\end{array}$ \\
\hline \multicolumn{5}{|l|}{ Fixed effects } \\
\hline \multicolumn{5}{|l|}{ Woman's age } \\
\hline $15-24^{\dagger}$ & & 1.00 & & 1.00 \\
\hline $25-34$ & & $1.06(0.84-1.33)$ & & $1.02(0.81-1.28)$ \\
\hline $35-49$ & & $0.81(0.62-1.08)$ & & $0.80(0.61-1.06)$ \\
\hline \multicolumn{5}{|l|}{ Level of education } \\
\hline No education $^{\dagger}$ & & 1.00 & & 1.00 \\
\hline Primary & & $0.82(0.69-0.96)^{*}$ & & $0.84(0.71-0.99)^{*}$ \\
\hline Secondary/Higher & & $0.73(0.56-0.96)^{*}$ & & $0.71(0.54-0.94)^{*}$ \\
\hline \multicolumn{5}{|l|}{ Wealth index } \\
\hline Poor $^{\dagger}$ & & 1.00 & & 1.00 \\
\hline Middle & & $0.82(0.70-0.98)^{*}$ & & $0.85(0.71-1.00)$ \\
\hline Rich & & $0.85(0.73-0.99)^{*}$ & & $0.89(0.75-1.06)$ \\
\hline \multicolumn{5}{|c|}{ Number of living children } \\
\hline $0-1^{\dagger}$ & & 1.00 & & 1.00 \\
\hline $2-3$ & & $1.90(1.54-2.34)^{* *}$ & & $1.91(1.55-2.35)^{* *}$ \\
\hline $4-5$ & & $2.83(2.21-3.62)^{* *}$ & & $2.79(2.18-3.57)^{* *}$ \\
\hline $6+$ & & $4.24(3.16-5.68)^{* *}$ & & $4.05(3.00-5.45)^{* *}$ \\
\hline \multicolumn{5}{|l|}{$\begin{array}{l}\text { Husband's desire for } \\
\text { children }\end{array}$} \\
\hline Both want same ${ }^{\dagger}$ & & 1.00 & & 1.00 \\
\hline Husband wants more & & $1.22(1.01-1.48)^{*}$ & & $1.24(1.03-1.50)^{*}$ \\
\hline Husband wants fewer & & $1.08(0.92-1.28)$ & & $1.08(0.92-1.27)$ \\
\hline Don't know & & $1.00(0.82-1.23)$ & & $1.02(0.83-1.25)$ \\
\hline \multicolumn{5}{|l|}{$\begin{array}{l}\text { Decision-maker on a } \\
\text { woman's healthcare }\end{array}$} \\
\hline Husband/partner alone ${ }^{\dagger}$ & & 1.00 & & 1.00 \\
\hline Respondent alone & & $0.92(0.75-1.12)$ & & $0.98(0.80-1.19)$ \\
\hline Joint decision & & $0.83(0.70-0.99)^{*}$ & & $0.84(0.71-1.00)$ \\
\hline Others & & $1.01(0.14-7.20)$ & & $1.31(0.19-8.93)$ \\
\hline \multicolumn{5}{|l|}{ Working status } \\
\hline Not working $^{\dagger}$ & & 1.00 & & 1.00 \\
\hline
\end{tabular}


Working

Living arrangement

Woman stays with partner $^{\dagger}$

Woman stays alone

History of child death

$\mathrm{No}^{\dagger}$

Yes

Access to family planning messages

$\mathrm{No}^{\dagger}$

Yes

Place of residence

Urban $^{\dagger}$

Rural

Distance to the health

facility

No problem ${ }^{\dagger}$

Big problem

Community education

Low $^{\dagger}$

High

Community wealth

Low $^{\dagger}$

High

Community women

\section{working}

Low $^{\dagger}$

High

Community use of modern

contraceptives

High $^{\dagger}$

Low

Community mean age at

marriage

Community mean age at

sexual debut

Community mean number

of living children

\section{Random effect}

Community level variance

(SE)

$\operatorname{ICC}(\%)$

PCV (\%)

Model fit statistics

Log likelihood

AIC
1.00

$2.38(1.95-2.92)^{* *}$

1.00

1.04(0.92-1.22)

1.00

$0.72(0.63-0.81)^{* *}$
$0.79(0.65-0.96) *$

1.00

$2.29(1.87-2.80)^{* *}$

1.00

$1.06(0.91-1.23)$

1.00

$0.75(0.66-0.85)^{* *}$

$\begin{array}{ll}1.00 & 1.00 \\ 0.90(0.71-1.13) & 0.84(0.65)\end{array}$

$\begin{array}{ll}1.00 & 1.00 \\ 1.19(1.03-1.37) * & 1.14(0.99-1.33)\end{array}$

$1.00 \quad 1.00$

$0.98(0.84-1.15) \quad 1.00(0.85-1.18)$

$1.00 \quad 1.00$

$0.87(0.74-1.02) \quad 0.96(0.80-1.15)$

$1.00 \quad 1.00$

0.98(0.84-1.14) $\quad 1.06(0.90-1.26)$

$1.00 \quad 1.00$

$2.27(1.99-2.60)^{* *} \quad 2.32(2.02-2.66)^{* *}$

$1.05(0.95-1.16) \quad 1.07(0.96-1.19)$

$0.97(0.87-1.08) \quad 0.97(0.86-1.08)$

$1.30(1.16-1.45)^{* *} \quad 1.11(0.99-1.26)$

$0.26(0.05)^{* *}$

$0.25(0.05)^{* *}$

$0.07(0.03)^{* *}$

$0.08(0.03)^{* *}$

7.4

7.1

2.0

2.4

3.8

73.1

69.2

the assessment was based on multivariate-multilevel logistic regression model. 
Table 7: Multilevel analysis of the association between individual and community factors with unmet need among married women in Tanzania

\begin{tabular}{|c|c|c|c|c|}
\hline Selected characteristic & Model 1 & $\begin{array}{l}\text { Model } 2 \\
\text { aOR }(95 \% \mathrm{CI})\end{array}$ & $\begin{array}{l}\text { Model } 3 \\
\text { aOR }(95 \% \mathrm{CI})\end{array}$ & $\begin{array}{l}\text { Model } 4 \\
\text { aOR }(95 \% \mathrm{CI})\end{array}$ \\
\hline \multicolumn{5}{|l|}{ Fixed effects } \\
\hline \multicolumn{5}{|l|}{ Woman's age } \\
\hline $15-24^{\dagger}$ & & 1.00 & & 1.00 \\
\hline $25-34$ & & $0.68(0.58-0.79)^{* *}$ & & $0.71(0.59-0.85)^{* *}$ \\
\hline $35-49$ & & $0.64(0.53-0.77)^{* *}$ & & $0.62(0.49-0.77)^{* *}$ \\
\hline \multicolumn{5}{|l|}{ Level of education } \\
\hline No education $^{\dagger}$ & & 1.00 & & 1.00 \\
\hline Primary & & $0.88(0.77-1.01)$ & & $0.98(0.84-1.14)$ \\
\hline Secondary/Higher & & $0.91(0.75-1.12)$ & & $0.93(0.73-1.19)$ \\
\hline \multicolumn{5}{|l|}{ Wealth index } \\
\hline Poor $^{\dagger}$ & & 1.00 & & 1.00 \\
\hline Middle & & $0.79(0.68-0.91)^{* *}$ & & $0.91(0.77-1.08)$ \\
\hline Rich & & $0.61(0.53-0.71)^{* *}$ & & $0.66(0.53-0.82)^{* *}$ \\
\hline \multicolumn{5}{|l|}{ Number of living children } \\
\hline $0-1^{\dagger}$ & & 1.00 & & 1.00 \\
\hline $2-3$ & & $1.93(1.66-2.25)^{* *}$ & & $1.90(1.59-2.28)^{* *}$ \\
\hline $4-5$ & & $2.50(2.06-3.04)^{* *}$ & & $2.49(1.97-3.15)^{* *}$ \\
\hline $6+$ & & $3.70(2.96-4.63)^{* *}$ & & $3.74(2.86-4.89)^{* *}$ \\
\hline \multicolumn{5}{|l|}{$\begin{array}{l}\text { Husband's desire for } \\
\text { children }\end{array}$} \\
\hline Both want same ${ }^{\dagger}$ & & 1.00 & & 1.00 \\
\hline Husband wants more & & $1.28(1.13-1.45)^{* *}$ & & $1.17(1.01-1.35)^{*}$ \\
\hline Husband wants fewer & & $1.22(0.98-1.50)$ & & $1.16(0.90-1.49)$ \\
\hline Don't know & & $0.83(0.73-0.94)^{* *}$ & & $0.88(0.76-1.01)$ \\
\hline \multicolumn{5}{|l|}{$\begin{array}{l}\text { Decision-maker on a } \\
\text { woman's healthcare }\end{array}$} \\
\hline Husband/partner alone $^{\dagger}$ & & 1.00 & & 1.00 \\
\hline Respondent alone & & $1.20(1.03-1.40)^{*}$ & & $1.13(0.94-1.35)$ \\
\hline Joint decision & & $0.89(0.80-1.00)^{*}$ & & $0.91(0.80-1.04)$ \\
\hline Others & & $0.43(0.17-1.07)$ & & $0.40(0.14-1.17)$ \\
\hline \multicolumn{5}{|l|}{ Working status } \\
\hline Not working $^{\dagger}$ & & 1.00 & & 1.00 \\
\hline Working & & $0.64(0.57-0.73)^{* *}$ & & $0.69(0.59-0.80)^{* *}$ \\
\hline \multicolumn{5}{|l|}{ Living arrangement } \\
\hline Woman stays with partner ${ }^{\dagger}$ & & 1.00 & & 1.00 \\
\hline Woman stays alone & & $2.04(1.72-2.43)^{* *}$ & & $1.45(1.17-1.79)^{* *}$ \\
\hline \multicolumn{5}{|l|}{ History of child death } \\
\hline $\mathrm{No}^{\dagger}$ & & 1.00 & & 1.00 \\
\hline Yes & & $1.11(0.98-1.25)$ & & $1.10(0.96-1.27)$ \\
\hline
\end{tabular}


Access to family planning messages

$\mathrm{No}^{\dagger}$

1.00

1.00

Yes

$0.84(0.76-0.94)^{* *}$

$0.91(0.80-1.03)$

Place of residence

Urban $^{\dagger}$

Rural

Distance to the health

facility

No problem ${ }^{\dagger}$

$1.00 \quad 1.00$

Big problem

0.93(0.84-1.02)

$\begin{array}{ll}1.00 & 1.00 \\ 0.65(0.54-0.79) * * & 0.73(0.59-0.90) * *\end{array}$

Community education

Low $^{\dagger}$

$1.00 \quad 1.00$

High

Community wealth

Low $^{\dagger}$

High

Community women

working

Low $^{\dagger}$

$1.00 \quad 1.00$

High

Community use of modern

contraceptives

$\mathrm{High}^{\dagger}$

$0.83(0.70-0.98)^{*}$

$0.97(0.81-1.17)$

Low

1.00

1.00

$0.85(0.69-1.04)$

$1.20(0.95-1.51)$

Community mean age at

marriage

Community mean age at

sexual debut

Community mean number

$0.95(0.83-1.08) \quad 1.05(0.90-1.22)$

of living children

\section{Random effect}

Community level variance

(SE)

$\operatorname{ICC}(\%)$

PCV $(\%)$

1.00

1.00

$2.29(2.01-2.60)^{* *}$

$2.33(2.02-2.69)^{* *}$

$1.06(1.01-1.12)^{*}$

$1.09(1.02-1.16)^{* *}$

$0.93(0.87-0.99)^{*} \quad 0.90(0.84-0.97)^{* * *}$

$1.37(1.26-1.49)^{* *} \quad 1.22(1.12-1.34)^{* * *}$

Model fit statistics

Log likelihood

$0.49(0.06)^{* *}$

$0.39(0.05)^{* *}$

$0.19(0.03)^{* *}$

$0.12(0.03)^{* *}$

AIC

12.9

10.6

5.4

3.6

20.4

61.2

75.5

$\dagger$ is a Reference category, * Significant at $p<0.05$, ** significant at $p<0.01 ;$ aOR is the adjusted odds ratio; the assessment was based on multivariate-multilevel logistic regression model. 
Table 8: Multilevel analysis of the association between individual and community factors with unmet need among married women in Uganda

\begin{tabular}{|c|c|c|c|c|}
\hline Selected characteristic & Model 1 & $\begin{array}{l}\text { Model } 2 \\
\text { aOR }(95 \% \mathrm{CI})\end{array}$ & $\begin{array}{l}\text { Model } 3 \\
\text { aOR }(95 \% \mathrm{CI})\end{array}$ & $\begin{array}{l}\text { Model } 4 \\
\text { aOR }(95 \% \mathrm{CI})\end{array}$ \\
\hline \multicolumn{5}{|l|}{ Fixed effects } \\
\hline \multicolumn{5}{|l|}{ Woman's age } \\
\hline $15-24^{\dagger}$ & & 1.00 & & 1.00 \\
\hline $25-34$ & & $0.74(0.65-0.83)^{* *}$ & & $0.77(0.68-0.87)^{* *}$ \\
\hline $35-49$ & & $0.70(0.60-0.82)^{* *}$ & & $0.75(0.64-0.88)^{* *}$ \\
\hline \multicolumn{5}{|l|}{ Level of education } \\
\hline No education ${ }^{\dagger}$ & & 1.00 & & 1.00 \\
\hline Primary & & $0.88(0.77-1.02)$ & & $0.93(0.81-1.07)$ \\
\hline Secondary/Higher & & $0.69(0.59-0.81)^{* *}$ & & $0.76(0.64-0.90)^{* *}$ \\
\hline \multicolumn{5}{|l|}{ Wealth index } \\
\hline Poor $^{\dagger}$ & & 1.00 & & 1.00 \\
\hline Middle & & $0.90(0.80-1.01)$ & & $0.99(0.88-1.11)$ \\
\hline Rich & & $0.70(0.62-0.78)^{* *}$ & & $0.86(0.76-0.97)^{*}$ \\
\hline \multicolumn{5}{|l|}{ Number of living children } \\
\hline $0-1^{\dagger}$ & & 1.00 & & 1.00 \\
\hline $2-3$ & & $1.61(1.42-1.83)^{* *}$ & & $1.61(1.42-1.83)^{* *}$ \\
\hline $4-5$ & & $2.11(1.79-2.47)^{* *}$ & & $2.04(1.74-2.40)^{* *}$ \\
\hline $6+$ & & $2.66(2.21-3.21)^{* *}$ & & $2.54(2.10-3.07) * *$ \\
\hline \multicolumn{5}{|l|}{$\begin{array}{l}\text { Husband's desire for } \\
\text { children }\end{array}$} \\
\hline Both want same ${ }^{\dagger}$ & & 1.00 & & 1.00 \\
\hline Husband wants more & & $1.05(0.95-1.16)$ & & $1.06(0.96-1.17)$ \\
\hline Husband wants fewer & & $0.98(0.85-1.13)$ & & $0.99(0.86-1.14)$ \\
\hline Don't know & & $0.90(0.80-1.00)^{*}$ & & $0.89(0.80-1.00)^{*}$ \\
\hline \multicolumn{5}{|l|}{$\begin{array}{l}\text { Decision-maker on a } \\
\text { woman's healthcare }\end{array}$} \\
\hline Husband/partner alone ${ }^{\dagger}$ & & 1.00 & & 1.00 \\
\hline Respondent alone & & $0.94(0.85-1.05)$ & & $0.93(0.83-1.03)$ \\
\hline Joint decision & & $0.84(0.76-0.93)^{* *}$ & & $0.83(0.75-0.91)^{* *}$ \\
\hline Others & & $1.31(0.67-2.55)$ & & $1.28(0.66-2.47)$ \\
\hline \multicolumn{5}{|l|}{ Working status } \\
\hline Not working $^{\dagger}$ & & 1.00 & & 1.00 \\
\hline Working & & $0.86(0.78-0.95)^{* *}$ & & $0.85(0.77-0.94)^{* *}$ \\
\hline \multicolumn{5}{|l|}{ Living arrangement } \\
\hline Woman stays with partner ${ }^{\dagger}$ & & 1.00 & & 1.00 \\
\hline Woman stays alone & & $1.19(1.07-1.33)^{* *}$ & & $1.15(1.03-1.29)^{*}$ \\
\hline \multicolumn{5}{|l|}{ History of child death } \\
\hline $\mathrm{No}^{\dagger}$ & & 1.00 & & 1.00 \\
\hline Yes & & $1.03(0.94-1.14)$ & & $1.02(0.93-1.13)$ \\
\hline \multicolumn{5}{|l|}{$\begin{array}{l}\text { Access to family planning } \\
\text { messages }\end{array}$} \\
\hline $\mathrm{No}^{\dagger}$ & & 1.00 & & 1.00 \\
\hline Yes & & $1.03(0.94-1.12)$ & & $1.05(0.96-1.15)$ \\
\hline \multicolumn{5}{|l|}{ Place of residence } \\
\hline Urban $^{\dagger}$ & & & 1.00 & 1.00 \\
\hline Rural & & & $0.86(0.75-1.00)^{*}$ & $0.84(0.73-0.97)^{*}$ \\
\hline
\end{tabular}




\section{Distance to the health}

\section{facility}

No problem ${ }^{\dagger}$

$\begin{array}{ll}1.00 & 1.00 \\ 1.14(1.04-1.25)^{* * *} & 1.17(1.07-1.27)^{* *}\end{array}$

Big problem

Community education

Low $^{\dagger}$

High

\section{Community wealth}

Low $^{\dagger}$

High

\section{Community women}

working

Low $^{\dagger}$

$1.00 \quad 1.00$

$0.96(0.85-1.08) \quad 0.99(0.86-1.12)$

High

$\begin{array}{ll}1.00 & 1.00 \\ 0.82(0.73-0.93)^{* *} & 0.86(0.75-0.99)^{*}\end{array}$

$1.00 \quad 1.00$

Community use of modern

$1.05(0.95-1.16)$

1.04(0.93-1.16)

\section{contraceptives}

High $^{\dagger}$

1.00

$2.07(1.87-2.30)^{* *}$

1.01(0.97-1.06)

Community mean age at

marriage

Community mean age at

sexual debut

Community mean number

of living children

\section{Random effect}

Community level variance

(SE)

$\operatorname{ICC}(\%)$

PCV $(\%)$

Model fit statistics

Log likelihood $\quad-8,040$

AIC

\section{$0.35(0.04)^{* *}$ \\ $0.26(0.03) * *$}

$0.91(0.86-0.96)^{* *}$

$1.16(1.09-1.25)^{* *}$

7.4

25.7

9.7

7.4

3.4
1.00

2.14(1.92-2.37)**

1.04(0.99-1.09)

$0.92(0.86-0.98) * *$

$1.05(0.98-1.13)$

$0.11(0.02)^{* *}$

3.7

68.6

$\dagger$ is a Reference category, ${ }^{*}$ Significant at $p<0.05, * *$ significant at $p<0.01 ;$ aOR is the adjusted odds ratio; the assessment was based on multivariate-multilevel logistic regression model.

\section{Discussion}

The study explored both individual and community factors associated with unmet need for contraception among married women in Burundi, Rwanda, Tanzania and Uganda using data from their most recent DHS. Results indicate that unmet need for contraception in the four countries ranged from $20 \%$ in Rwanda to $33 \%$ in Burundi. The proportion of married women with unmet need for contraception is similar to that reported in 2016-2017 Burundi DHS, 20142015 Rwanda DHS, 2015-2016 Tanzania DHS and 2016 Uganda DHS [6, 7, 18, 19]. This seemingly high rate of unmet need could be explained by several individual and community factors. 
After controlling for both individual and community factors, result revealed that: woman's age, education level, wealth index, number of living children, husband's desire for children, decision on woman's health care, history of child death, working status, access to family planning messages, place of residence, distance to health facility, community wealth, community women working, community use of modern contraceptives, community age at marriage, community age at sexual debut and community mean number of living children were significantly associated with unmet need for contraception in at least one of the countries or in the pooled model.

Results showed that older married women were at lower risk of experiencing unmet need for contraception in Burundi, Tanzania and Uganda as compared to the young ones. This finding is comparable with other studies conducted elsewhere[23]. Older women are assumed to have a more in-depth knowledge on the benefits (or risks) of using (not using) contraceptives as compared to their young counterparts.

In regard to education, educated women in Burundi, Rwanda and Uganda were less likely to experience unmet need as compared to illiterates. This finding was in agreement with earlier findings in Burundi[15] and Pakistani [23]. Relatedly, women in Burundi, Tanzania and Uganda who were from higher wealth quintile were less likely to experience unmet need for contraceptives as compared to those in the lowest quintile concurring with prior studies [15, $23,24]$. The possible explanation could be that education and better economic status empower women with quality information and exposure to different modern contraceptives. This makes them make informed choices regarding the best contraceptive methods that suit their needs in regulating fertility.

The findings also revealed that, unmet need for contraception among married women was associated with higher number of living children in all the four countries. This was in agreement with findings in Kenya [25]. Prior studies have linked women with higher number of living children to higher odds of using contraceptive [22, 26, 27] which may not be the case in this finding. The explanation to this finding could be attributed to cultural and societal norms in these countries. In a study carried out in Uganda on the socio-cultural inhibitors to use of modern contraceptive, revealed that the belief people have that all children are God given, sociocultural and traditional practices used to limit and space births [28]. In addition, we think the low empowerment among women and the perception that men prefer many children make women who already have many children not to prevent further pregnancies [28, 29] .

Similarly, married women whose husbands had a higher desire for children were more likely to experience unmet need for contraception in Burundi, Rwanda and Tanzania. According to 
the 2015-16 TDHS, women were more likely to have a smaller family size as compared to men [7]. Studies have also highlighted that men are more likely to want to have another child than women regardless of how many children they already have[6]. It is therefore evident that the cultural beliefs that some of the women have where the more children a man has, the prouder and heroic he becomes in a community [29] coupled with their low decision making powers in a home explain this high level of unmet need.

Relatedly, women who make joint decisions with their partners regarding their health were less likely to report unmet need for contraception in Burundi and Uganda as compared to those whose health decisions are entirely made by husbands. Prior studies have showed that a woman's intention to use contraception is partly driven by a man's decision making on health care services [30] and couples discussion on family planning [31]. Mboane and Madhav revealed that, despite the knowledge on modern contraceptive methods and the desire to limit the family size, a woman's use of contraception is influenced by her husband's decision and approval regardless of the number of living children they may be having [32]. Therefore, husbands have an important role in contraceptive uptake of their wives, with their decisions and approvals likely to impact on the level of unmet need.

With the exception of Burundi, married women in Rwanda, Tanzania and Uganda who were working at the time of the survey were significantly associated with reduced odds of unmet need for contraception as compared to those who were not working. This was consistent with the findings in Pakistani [23] and Malawi [33]. The reason for this could be that women who are working are empowered in making decisions regarding their preferred family size and are also more concerned in surrendering their time to get income than giving birth and looking after children all the time. Young married women in Zambia stressed that family planning gives them an opportunity to plan in spacing their births and fully concentrate on work without any disturbance [34].

Our study also showed that married women who were not living with their partners at the time of the survey in all the four countries considered were significantly associated with increased odds of unmet need for contraception. The reasons surrounding the high levels of unmet need among couples who are not temporarily staying together requires further qualitative investigations. In assessing the impact of male migration on contraceptive use, unmet need and fertility in 2013, Khanal, and colleagues also revealed similar findings that the high increase in unmet need in Nepal was driven by women whose husbands have been away for less than one year [35]. 
We also found out that married women in Burundi who had a history of child death had a higher likelihood of unmet need for contraception. Such women may not use contraceptives in order to replace the dead child or may continue to produce in order to be more secure in case of another further death irrespective of current number of living children they have. This finding concurred with the earlier finding in Burundi where Nzokirishaka and Itua revealed that a loss of a girl child was significantly associated with unmet need for limiting while that of a son being linked to both unmet needs for limiting and total unmet need [15].

The results also indicated that married women in Burundi and Rwanda who had access to family planning messages through any media were less likely to report unmet need. Different forms of media help to educate women on the importance of various modern contraceptive methods including the approaches to accessing each method. This finding is in line with previous studies [15, 23, 25, 33].

In relation to the community, surprisingly, married women in rural areas were less likely experience unmet need for contraception as compared to their counterparts in urban areas both in Tanzania and Uganda. This finding contradicted with previous studies[23, 36-38]. Basing on the use of cross-sectional data, this finding is rather counter intuitive which requires, further investigations. However, similar findings have also been observed in other countries where unmet need among women in urban areas is higher as compared to women in rural areas[39, 40].

Regarding the distance to the health facility, married women in Uganda who highlighted that this distance was a big problem were more likely to report unmet need for contraception. Ettarh and Kyobutungi in a study on physical access to health facilities and contraceptive use in Kenya revealed that, physical proximity to health facilities is very vital in the health-seeking behavior in a community [40]. Long distances have been identified to be linked to low uptake and utilization of health services in several developing countries [23, 27-29]. Further, when it comes to accessing family planning services, long distances frustrate women who would have wished to consistently use different modern methods and as a result leading to discontinuation and intermittent use [34].

Unmet need for contraception has been also shown to be higher in communities where women have low uptake of modern contraceptive use in Burundi, Rwanda, Tanzania and Uganda. This was consistent with the findings in Bangladesh [37]. Similarly, McGuire and Stephenson in their study about the community factors influencing birth spacing among married women in Uganda and Zimbabwe revealed that women who were living in communities with lower levels 
of contraceptive use were associated with short birth intervals [43]. Still, communities with high knowledge of modern contraceptive have been also known to be associated with reduced odds of unmet need[44]. This implies that women living in communities with high contraceptive use can freely interact and share better knowledge with each other on different modern contraceptive methods thereby extremely lowering the level of unmet need.

Community level of wealth was also a significant community characteristic affecting unmet need for contraceptives among married women in Uganda. The reason for this could be that; in economically wealthier communities, women are likely to be more educated, have high decision making powers regarding their health and the access to health facilities may be easier. Therefore, women can easily share knowledge and learn from each other the benefits of using family planning methods. This finding is consistent with findings among Malawian women [33].

Also, the findings in Tanzania, women living in communities in which there was a higher mean age at first marriage had higher odds of unmet need for contraception. Other studies in America and south east Asia have also linked a higher community mean age at marriage with low contraceptive use [45]. A higher community age at first marriage is likely to be associated with higher community education and therefore this may make women within the communities to postpone their time to have children. However, to compensate for lost time so as to achieve their desired number of children, they may be prone to higher levels of unmet need.

Relatedly, women who were living in communities in Tanzanian and Ugandan with higher mean age at first sexual debut were less likely to have unmet need for contraception. Studies have associated higher community mean age at sexual debut with high modern contraceptive use elsewhere [45]. The possible explanation could be that women living in areas with higher age at sexual debut tend to have higher level of educational attainment and highly empowered in making decisions regarding their health including use of modern contraceptives. Such women will therefore freely share information with their peers regarding family planning services.

Further, regarding community mean number of living children, results showed that married women in communities with higher number of living children in Burundi and Tanzania had higher odds of unmet need compared to that married women in communities with lower number of living children. Women living in such communities are significantly associated with low modern contraceptive use [45]. The combination of low uptake of modern contraceptives, low education levels and low levels of autonomy make women in such communities not to 
have reliable information on how to have a desired family size and the different knowledge on family planning.

\section{Strengths and limitations of the study}

The strength of this study is that it is based on a nationally representative sample of married women in Burundi, Rwanda, Tanzania and Uganda. Therefore, the results generated from the analysis may be generalized to all married women in the four countries. Still, the study applied multilevel modeling to accommodate the hierarchical nature of the DHS data in order to identify the contribution of individual and community characteristics on unmet need. A variety of factors were also assessed in this study to strengthen the associations observed. Despite the above strengths, the study has the following limitations. The data used is not only crosssectional but also purely quantitative in nature and therefore we are unable to determine causation. The study therefore misses the qualitative individual and community aspects surrounding the level of unmet need in the four countries.

\section{Conclusion}

The study showed that both individual and community level characteristics were important in explaining unmet need in Burundi, Rwanda, Tanzania and Uganda. Young married women, low education level, low wealth quintile, higher number of living children, women that were not staying with their partners, husband's desire for more children, history of child death, women who are not working, no access to family planning messages, long distances to health facilities, husbands as decision-makers on women's health care, low community wealth, low community use of modern contraceptives, higher community age at marriage, higher community mean number of living children and lower community age at sexual debut were found to be significantly associated with high risk of unmet need for contraception in at least one of the countries.

The findings suggest the need to design programs and policies that ensure awareness and access to modern contraceptive services among all disadvantaged communities and unique groups like couples who are not staying together through increased outreaches and increased mass media campaigns. In addition, raising the educational levels of people to bring about change in social and cultural norms that influence the husbands desire for higher number of children and empowering women through job creation will significantly reduce the level of unmet need for contraception. 


\section{Abbreviations}

AOR: Adjusted odds ratios; CI: Confidence interval; FP: Family Planning; ICC: Intra cluster correlation; OR: Odds ratio; PCV: Proportional change in variance; DHS: Demographic and Health Survey.

\section{Acknowledgements}

The authors would like to thank the MEASURE DHS for making this data publically available for analysis. Special thanks to Makerere University College of Business and Management Sciences (CoBAMS) for supporting the writing process of this manuscript.

\section{Availability of data and materials}

The dataset used and analyzed in this paper is available from the DHS program site upon request: http://dhsprogram.com/data/

\section{Author contribution}

AK and RW conceptualized and designed the study. RW and AK performed the statistical analysis and jointly wrote the first draft manuscript. RW, AK, NH, JS, AP and JCR contributed to writing the literature review and interpretation of the results. JCR contributed to the review of scientific contents of the manuscript and the discussion. All authors reviewed the manuscript and agreed on the findings and views expressed. All authors read, reviewed and approved the final version of the manuscript. The authors agreed to abide by the copyright terms and conditions of BioMed Central.

\section{Ethics approval and consent to participate}

Not applicable

\section{Funding}

This research did not receive any funding. 


\section{References}

1. Bradley SEK, Croft TN, Fishel JD, Westoff CF. Revising Unmet Need for Family Planning. DHS Analytical Studies No. 25. Calverton, Maryland, USA: ICF International; 2012.

2. United Nations Department of Economic and Social Affairs Population Division. Contraceptive Use by Method 2019. New York; 2019.

3. United Nations Department of Economic and Social Affairs Population Division. World Fertility and Family Planning 2020. New York; 2020.

4. Melhado L. Unmet Need for Contraceptives in Developing World Has Declined , But Remains High in Some Countries. Int Perspect Sex Reprod Health. 2013;39:163-4.

5. Wang W, Staveteig S, Winter R, Allen C. Women's Marital Status, Contraceptive Use, and Unmet Need in Sub-Saharan Africa, Latin America, and the Caribbean. Rockville, Maryland, USA; 2017.

6. Uganda Bureau of Statistics and ICF. Uganda Demographic and Health Survey 2016. . Kampala, Uganda and Rockville, Maryland, USA: UBOS and ICF; 2018.

7. Ministry of Health, Community Development, Gender, Elderly and Children (MoHCDGEC) [Tanzania Mainland], Ministry of Health $(\mathrm{MoH})$ [Zanzibar], National Bureau of Statistics (NBS), Office of the Chief Government Statistician (OCGS), and ICF. Tanzania Demographic and Health Survey and Malaria Indicator Survey (TDHS-MIS) 2015-16. Dar es Salaam, Tanzania, and Rockville, Maryland, USA; 2016.

8. Guttmacher Institute. Reasons for Unmet Need For Contraception in Developing Countries. New York; 2016.

9. Cahill N, Sonneveldt E, Stover J, Weinberger M, Williamson J, Wei C, et al. Modern contraceptive use, unmet need, and demand satisfied among women of reproductive age who are married or in a union in the focus countries of the Family Planning 2020 initiative: a systematic analysis using the Family Planning Estimation Tool. Lancet. 2018;391:870-82. http://dx.doi.org/10.1016/ S0140-6736(17)33104-5.

10. Sedgh G, Singh S, Hussain R. Intended and Unintended Pregnancies Worldwide in 2012 and Recent Trends. Stud Fam Plann. 2014;45:301-14.

11. Pav G, Boadi E. A decade of unmet need for contraception in Ghana: Programmatic and policy implications. Calverton, Maryland: Macro International Inc. and National Population Council Secretariat [Ghana]; 2000.

12. Dingeta T, Oljira L, Worku A, Berhane Y. Unmet Need for Contraception Among Young Married Women in Eastern Ethiopia. Open Access J Contracept. 2019;10:89-101.

13. Mohammed A, Envuladu EA, Okoh EO, Osagie IA, Danimoh MA, Zoakah AI. Unmet 
Need for Family Planning Among Women of Reproductive Age in Plateau State Nigeria. Int J Sci Res Manag. 2018;06:2018-101-7.

14. Edietah EE, Njotang PN, Ajong AB, Essi MJ, Yakum MN, Mbu ER. Contraceptive use and determinants of unmet need for family planning; a cross sectional survey in the North West Region, Cameroon. BMC Womens Health. 2018;18:1-8.

15. Nzokirishaka A, Itua I. Determinants of unmet need for family planning among married women of reproductive age in Burundi: a cross-sectional study. Contracept Reprod Med. 2018;3:1-13.

16. Ojakaa D. Trends and Determinants of Unmet Need for Family Planning in Kenya. Calverton, MD: Macro. International Inc; 2008.

17. Khan S, Bradley SE., Fishel J, Mishra V. Unmet Need and the Demand for Family Planning in Uganda: Further Analysis of the Uganda Demographic and Health Surveys, 1995-2006. Calverton, Maryland, USA; 2008.

18. Kenya National Bureau of Statistics, Ministry of Health, National AIDS Control Council, Kenya Medical Research Institute, National Council for Population and Development Nairobi, The DHS Program II. Kenya Demographic and Health Survey 2014. Nairobi, Kenya and Rockville, Maryland, USA; 2015.

19. Ministère à la Présidence chargé de la Bonne Gouvernance et du Plan [Burundi] (MPBGP), Ministère de la Santé Publique et de la Lutte contre le Sida [Burundi] (MSPLS), Institut de Statistiques et d'Études Économiques du Burundi (ISTEEBU) et I. Enquête Démographique et de Santé au Burundi 2016-2017: Rapport de synthèse. Rockville, Maryland, USA; 2018.

20. National Institute of Statistics of Rwanda (NISR) [Rwanda], Ministry of Health (MOH) [Rwanda] and II. Rwanda Demographic and Health Survey 2014-15. Rockville, Maryland, USA; 2015.

21. Kaggwa EB, Diop N, Storey JD. The Role of Individual and Community Normative Factors: A Multilevel Analysis of Contraceptive Use Among Women in Union in Mali. Int Fam Plan Perspect. 2008;34:79-88.

22. Abate MG, Tareke AA. Individual and community level associates of contraceptive use in Ethiopia : a multilevel mixed effects analysis. Arch Public Heal. 2019;77:1-12.

23. Asif MF, Pervaiz Z. Socio-demographic determinants of unmet need for family planning among married women in Pakistan. BMC Public Health. 2019;19:1-8.

24. Yalew M, Adane B, Kefale B, Damtie Y. Individual and community-level factors associated with unmet need for contraception among reproductive-age women in Ethiopia; a multi-level analysis of 2016 Ethiopia Demographic and Health Survey. BMC Public Health. 
2020;20:1-9.

25. Nyauchi B, Omedi G. Determinants of Unmet Need for Family Planning among Women in Rural Kenya. African Popul Stud. 2014;28:999-1008.

26. Andi JR, Wamala R, Ocaya B, Kabagenyi A. Modern contraceptive use among women in Uganda : An analysis of trend and patterns ( 1995-2011 ). Etude Popul Af. 2014;28:1009-21. 27. Habyarimana F, Ramroop S. The Analysis of Socio-Economic and Demographic Factors Associated with Contraceptive Use Among Married Women of Reproductive Age in Rwanda. Open Public Health J. 2018;11:348-59.

28. Kabagenyi A, Reid A, Ntozi J, Atuyambe L. Socio-cultural inhibitors to use of modern contraceptive techniques in rural Uganda: a qualitative study. Pan Afr Med J. 2016;25:6613. doi:10.11604/pamj.2016.25.78.6613.

29. Cyril A, Siaity E, Brownie S, Holroyd E. My husband will love me more if I give birth to more children : Rural women's perceptions and beliefs on family planning services utilization in a low resource setting. Int $\mathbf{J}$ Africa Nurs Sci. 2019;10 April:152-8. doi:10.1016/j.ijans.2019.04.005.

30. Kabagenyi A, Jennings L, Reid A, Nalwadda G, Ntozi J, Atuyambe L. Barriers to male involvement in contraceptive uptake and reproductive health services : a qualitative study of men and women' s perceptions in two rural districts in Uganda. Reprod Health. 2014;11:1-9. http://www.reproductive-health-journal.com/content/11/1/21.

31. Adebowale A, Palamuleni ME. Determinants of Unmet Need for Modern Contraception and Reasons for Non-use among Married Women in Rural Areas of Burkina Faso. African Popul Stud. 2014;28:499-514.

32. Mboane R, Bhatta MP. Influence of a husband' $s$ healthcare decision making role on a woman' $s$ intention to use contraceptives among Mozambican women. Reprod Health. 2015;12:1-8. doi:10.1186/s12978-015-0010-2.

33. Nkoka O, Mphande WM, Ntenda PAM, Milanzi EB, Kanje V, Guo SJG. Multilevel analysis of factors associated with unmet need for family planning among Malawian women. BMC Public Health. 2020;20:1-12. https://doi.org/10.1186/s12889-020-08885-1.

34. Silumbwe A, Nkole T, Munakampe MN, Milford C, Cordero JP, Kriel Y, et al. Community and health systems barriers and enablers to family planning and contraceptive services provision and use in Kabwe District , Zambia. BMC Health Serv Res. 2018;18:1-11. https://doi.org/10.1186/s12913-018-3136-4.

35. Khanal MN, Shrestha DR, Pant PD, Mehata S. Impact of Male Migration on Contraceptive Use, Unmet Need, and Fertility in Nepal. Calverton, Maryland, USA; 2013. 
36. Hailemariam A, Haddis F. Factors affecting unmet need for family planning in southern nations, nationalities and peoples region in Ethiopia. Ethiop J Heal Sci. 2011;21:77-89.

37. Pradhan J, Dwivedi R. Why Unmet Need for Family Planning Remains High in Bangladesh : A Community Level Analysis. J Women's Heal Care. 2015;4:1-7.

38. Ahinkorah BO. Predictors of unmet need for contraception among adolescent girls and young women in selected high fertility countries in sub- Saharan Africa: A multilevel mixed effects analysis. PLOSONE. 2020;15:1-15. doi:10.1371/journal.pone.0236352.

39. Ajmal S, Idris A, Ajmal B. Factors Affecting Contraceptive Use and Unmet Need among Currently Married Women in Afghanistan: Further Analysis of the 2015 Afghanistan Demographic and Health Survey. Rockville, Maryland, USA; 2018.

40. Ettarh RR, Kyobutungi C. Physical access to health facilities and contraceptive use in Kenya: Evidence from the 2008-2009 Kenya Demographic and Health Survey. Afr J Reprod Health. 2012;16:47-55.

41. Mekonnen ZA, Lerebo WT, Gebrehiwot TG, Abadura SA. Multilevel analysis of individual and community level factors associated with institutional delivery in Ethiopia. BMC Res Notes. 2015;8:1-9.

42. Jayaraman A, Gebreselassie T, Chandrasekhar S. Effect of Conflict on Age at Marriage and Age at First Birth in Rwanda. Popul Res Policy Rev. 2009;28:551-67.

43. Mcguire C, Stephenson R. Community Factors Influencing Birth Spacing among Married Women in Uganda and Zimbabwe. Afr J Reprod Health. 2015;19:14-24.

44. Solanke BL, Oyinlola FF, Oyeleye OJ, Ilesanmi BB. Maternal and community factors associated with unmet contraceptive need among childbearing women in Northern Nigeria. Contracept Reprod Med. 2019;4:1-12. https://doi.org/10.1186/s40834-019-0093-1.

45. Mutumba M, Wekesa E, Stephenson R. Community influences on modern contraceptive use among young women in low and middle-income countries : a cross- sectional multi-country analysis. BMC Public Health. 2018;18:1-9. https://doi.org/10.1186/s12889-018-5331-y. 


\section{Figures}

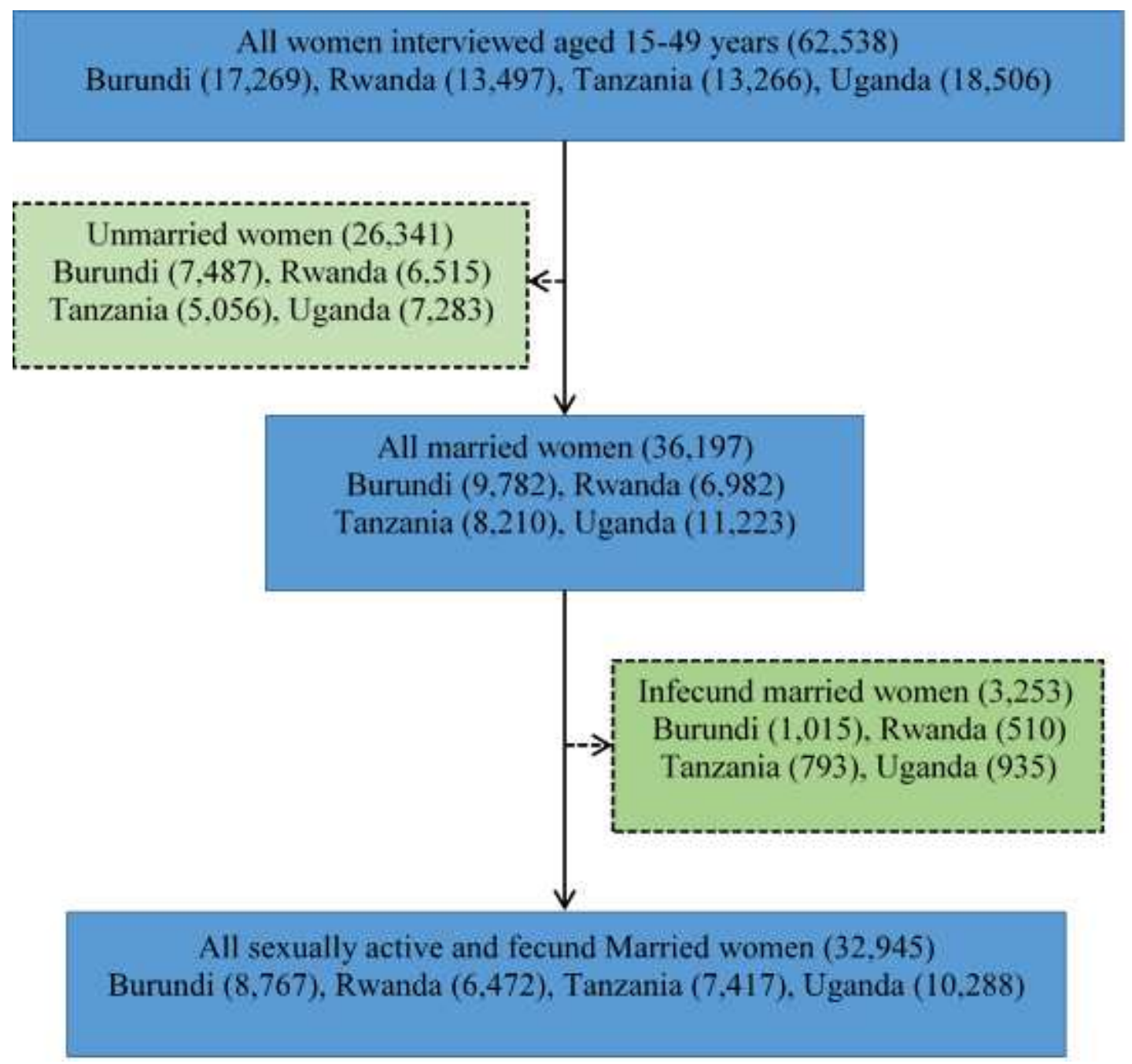

\section{Figure 1}

Derivation of the study sample 